Research Article

\title{
Sensitivity of Dynamical Downscaling Seasonal Precipitation Forecasts to Convection and Land Surface Parameterization in a High-Resolution Regional Climate Model
}

\author{
Yuan Li, Guihua Lu (D), Hai He $\mathbb{D}^{D}$, and Zhiyong Wu $\mathbb{D}$ \\ College of Hydrology and Water Resources, Hohai University, Nanjing 210098, China \\ Correspondence should be addressed to Hai He; hehai_hhu@hhu.edu.cn
}

Received 30 April 2019; Revised 17 September 2019; Accepted 1 October 2019; Published 20 November 2019

Academic Editor: Gabriele Buttafuoco

Copyright ( 2019 Yuan Li et al. This is an open access article distributed under the Creative Commons Attribution License, which permits unrestricted use, distribution, and reproduction in any medium, provided the original work is properly cited.

\begin{abstract}
Both convection and land surface parameterization influence seasonal precipitation forecasts. In this study, the sensitivity of dynamical downscaling seasonal precipitation forecasts to convection and land surface parameterization was investigated by nesting the Weather Research and Forecasting (WRF) model into the NCEP's Climate Forecast System version 2 (CFSv2) retrospective forecasts with four convective schemes: Kain-Fritsch (KF), Betts-Miller-Janjic (BMJ), Grell-Freitas (GF), and new simplified Arakawa-Schubert (NSAS) schemes, and two land surface schemes: Noah and simplified Simple Biosphere (SSiB) schemes over the Han River basin. The CFSv2 model biases are reduced when the KF convective scheme is used in the wet summer season. However, negative biases still exist especially when the combination of BMJ and SSiB schemes is used. Compared with CFSv2 reforecasts and other combinations of schemes, the forecast skills of spatial patterns of precipitation anomalies are highest when the combination of KF and Noah schemes is used in summer. In contrast, the combination of BMJ and SSiB schemes shows lowest forecast skills in summer. To understand the causes of the differences in precipitation forecasts using different parameterization schemes, the simulated moisture flux convergence, thermodynamic parameters at different pressure levels, convective available potential energy (CAPE), convective inhibition (CIN), and heat fluxes are compared with the data in the ERA-5 reanalysis dataset. The WRF model-simulated moisture flux convergence is closer to that of the ERA-5 reanalysis compared with that of the CFSv2 reforecasts in summer. The vertical thermodynamic profiles also suggest that the combination of the KF and Noah schemes has caused a more unstable atmosphere, which is crucial for precipitation. In contrast, the combination of BMJ and $\mathrm{SSiB}$ schemes shows a less unstable atmospheric environment in summer, which explains the lower forecast skills compared with other schemes. The spatial patterns of CAPE are also improved when using the WRF model, which further enhances the precipitation forecast skills over the Han River basin.
\end{abstract}

\section{Introduction}

Seasonal precipitation forecasts are essential for water management, disaster prevention, and many other aspects [1-3]. In recent years, coupled global circulation models (CGCMs), which use mathematical equations to describe the behaviour of large-scale circulations, have been developed. Many operational meteorological centers, including the National Centers for Environmental Prediction (NCEP), the European Centre for Medium-Range Weather Forecasts (ECMWF), and the Australian Bureau of Meteorology (BOM), have developed and released their own CGCMs
[4-6]. Many studies have proved that the sea surface temperature (SST) forecasts of CGCMs are comparable with statistical predictions [7, 8]. Jin et al. [9] evaluated the overall prediction skills for El Niño-Southern Oscillation (ENSO) with ten CGCMs and pointed out that the correlation skill of the tier-1 Multi-Model Ensemble (MME) forecast for the NINO3.4 SST anomalies reached 0.86 with a 6 -month lead. Seasonal precipitation forecasts remain a challenge due to the complexity of the climate system [10-12]. Precipitation is influenced not only by large-scale atmospheric circulations but also by small-scale processes such as convection and land surface interactions with the atmosphere, which influence 
spatial patterns of precipitation as well. Seasonal precipitation forecast skills of CGCMs are much lower than sea surface temperature, especially for the mid- and high-latitude areas [13-15].

Regional climate models (RCMs), whose lateral boundary conditions are derived from CGCMs, usually run at higher horizontal resolutions and can provide additional details for small-scale processes. Research has indicated that given "perfect" boundary forcing, RCMs can improve the representation of the North American Monsoon System (NAMS), both its climatology and interannual variability $[16,17]$. However, large uncertainties still exist in RCMs. Feser et al. [18] pointed out that improving RCMs depends on the experimental setup, analysed model variable, and location. Physical parameterizations, which are used to resolve small-scale physical processes, influence the ability of RCMs to add value. Liang et al. [19] reported that the Kain-Fritsch (KF) convection scheme performs better than the Grell scheme in North America, whereas the Grell scheme has its own compelling advantages for the Atlantic Ocean and Midwest. Yang et al. [20] tested five key parameters in the latest KF scheme over the Southern Great Plains, and the results indicated that the model bias for daily precipitation could be significantly reduced using five optimal parameters, especially for heavy precipitation. Xue et al. [21] compared the results from an Eta-SSiB biophysical coupled model with those from an Eta-bucket model and found a more realistic description of land surface processes could improve monthly precipitation forecasts over the U.S. It has been found by de Elía et al. [22] that a more realistic treatment of snow physics in a multilayer snow model could improve snow-pack simulations.

Most RCM parameterization sensitivity analyses take only one aspect into consideration, which is inadequate due to the complexity of the climate system. The cumulus convective processes influence the generation of precipitation directly and result in significant changes to land surface characteristics, such as soil moisture and surface albedo. These changes influence the land surface interactions with the atmosphere, such as latent heat fluxes and sensible heat fluxes, which, in turn, impact atmospheric stability. Therefore, land surface processes, convection, and other processes should be taken into consideration simultaneously. Crétat et al. [23] compared simulations of summer precipitation in Southern Africa using different physical parameterizations. The results indicated that intensity and other characteristics of summer precipitation are predominantly sensitive to convective schemes and affected less by the planetary boundary layer and microphysics schemes. Pei et al. [24] investigated the effects of the land surface model and convective parameterization on the simulation of short-term climate extremes. The results indicated that land surface processes strongly affect the precipitation amount, while the convective parameterization has considerable impacts on the precipitation pattern. However, different parameterization schemes have different impact on seasonal precipitation forecasts over different regions. Sensitivity analysis is still required for regional-scale precipitation forecasts.
Our previous studies have investigated the influence of convective parameterization on seasonal precipitation forecasts using the Weather and Research Forecasting model over the Han River basin [25]. The results suggested that convective parameterization played an important role in seasonal precipitation forecasts and that higher spatial resolution may potentially improve forecast skills. However, the influence of land surface parameterization on seasonal precipitation forecasts and the comparison between convective parameterization and land surface parameterization have not yet been studied. In this study, four convective parameterization schemes and two land surface parameterization schemes were selected to investigate the influence of both convection and land surface processes on seasonal precipitation forecasts over the Han River basin. Section 2 briefly introduces the study area, the designation of numerical experiments, and the verification data. Section 3 examines the large-scale circulations and surface energy balances to explain the main causes of the precipitation differences between parameterization schemes. Conclusions are summarized in Section 4.

\section{Study Area, Experimental Design, and Evaluation}

2.1. Study Area. The Han River basin is located between 106 and $114^{\circ} \mathrm{E}$ and between 30 and $34^{\circ} \mathrm{N}$ covering an area of nearly $170,000 \mathrm{~km}^{2}$ and is greatly affected by the East Asian monsoon (Figure 1(a)). The land use of the upper subbasin is mostly dominated by mixed forests, while the middle and lower subbasins are mostly dominated by crops (Figure 1(b)). Precipitation in this region shows high seasonal variability. The amount of precipitation in summer is always much higher than that in spring and autumn. Winter is much drier than other seasons, during which the averaged precipitation is always less than $1 \mathrm{~mm}$ /day (Figure 2 and Table 1). Researches have indicated that the coupling of soil moisture with precipitation is relatively high in the Han River basin compared with other regions worldwide [26]. The Danjiangkou Reservoir, located in the upper Han River basin, is the water source for the middle route of the Southto-North Water Diversion Project (SNWDP). The investigation of seasonal precipitation forecasts over this region is of great importance to both flood prevention and water resource management in China.

2.2. Experimental Design. In order to be aligned with previous studies, the model setting was the same as that of $\mathrm{Li}$ et al. [25] except for the selection of land surface parameterization schemes. The version of the Weather Research and Forecasting (WRF) model (http://www.wrf-model.org/ index.php) was 3.5. The horizontal resolution of the outer domain D01 was $30 \mathrm{~km}$ and that of the inner domain was $10 \mathrm{~km}$ (Figure 1). All domains were discretized with 38 vertical sigma levels with the model top at 50 mbar. Furthermore, the temporal coverage was extended from 2001-09 to 1999-2010. The lateral and boundary conditions were updated every six hours from the CFSv2 retrospective 


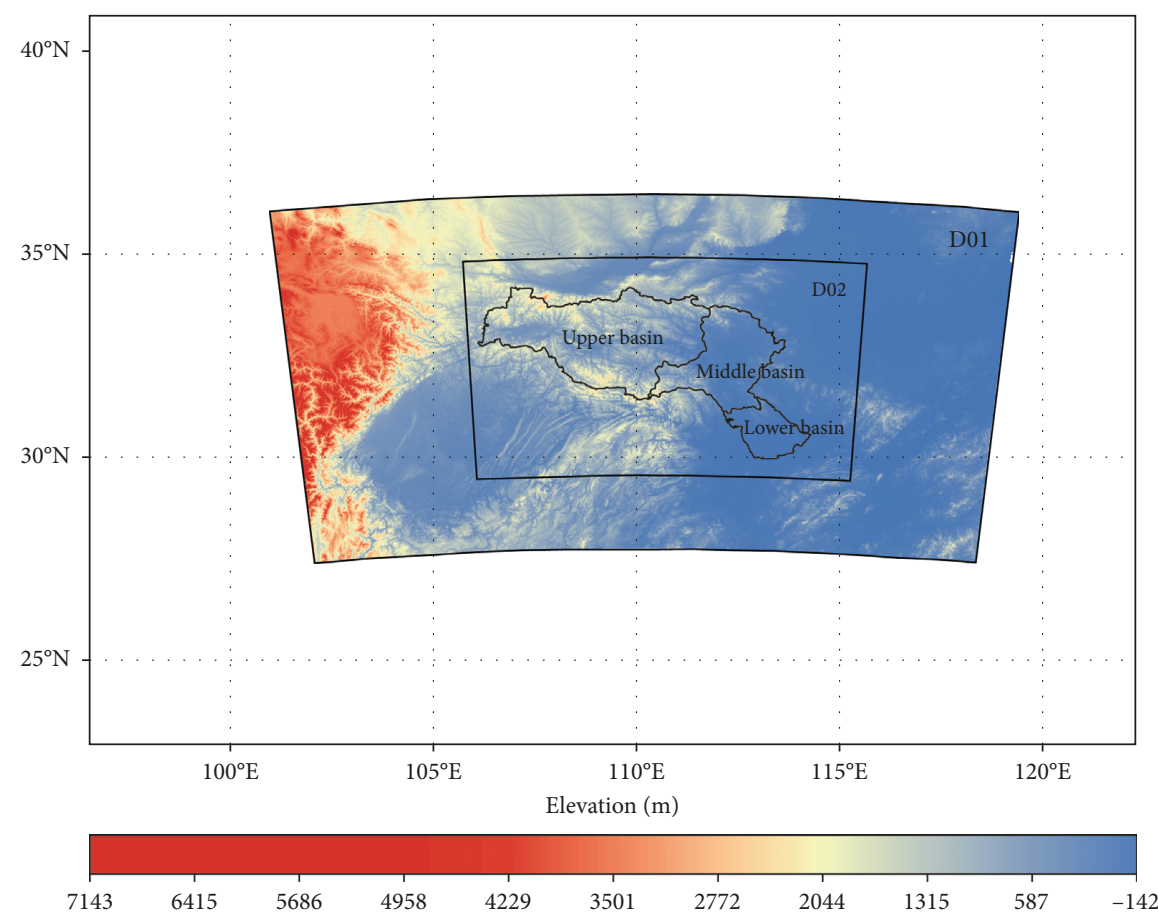

(a)

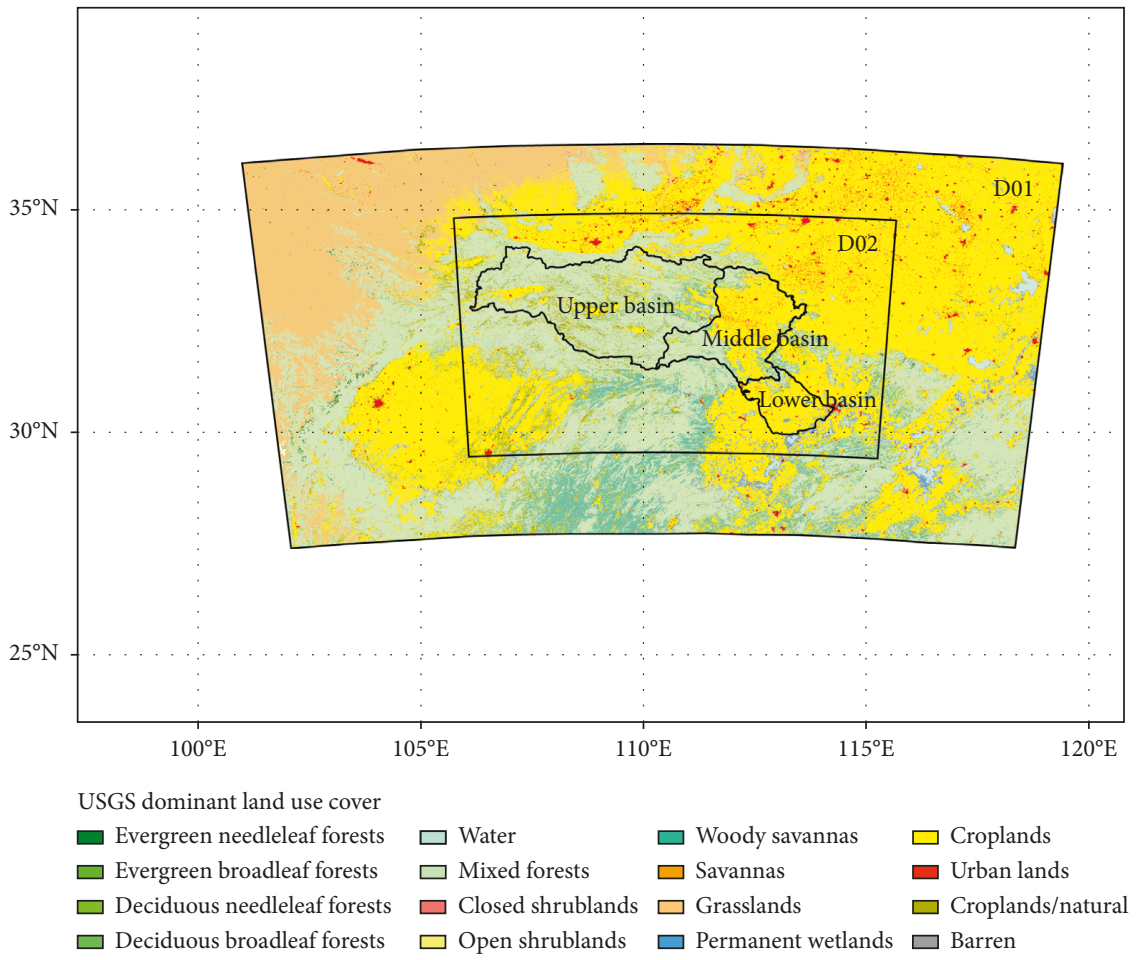

(b)

FIGURE 1: (a) WRF model domain configuration and (b) land use cover type derived from the U.S. Geological Survey (USGS) Long Term Archive.

forecasts. All model atmospheric settings were kept unchanged except for the adopted convective and land surface parameterization scheme. The physical parameterization schemes used for the simulations were as follows: the Ferrier scheme for microphysics parameterization the Yonsei
University scheme for planetary boundary layer parameterization [27], the Dudhia scheme for shortwave parameterization [28], and the RRTM for longwave radiation parameterization [29]. The WRF model integrated four months for spring, summer, autumn, and winter seasons, 


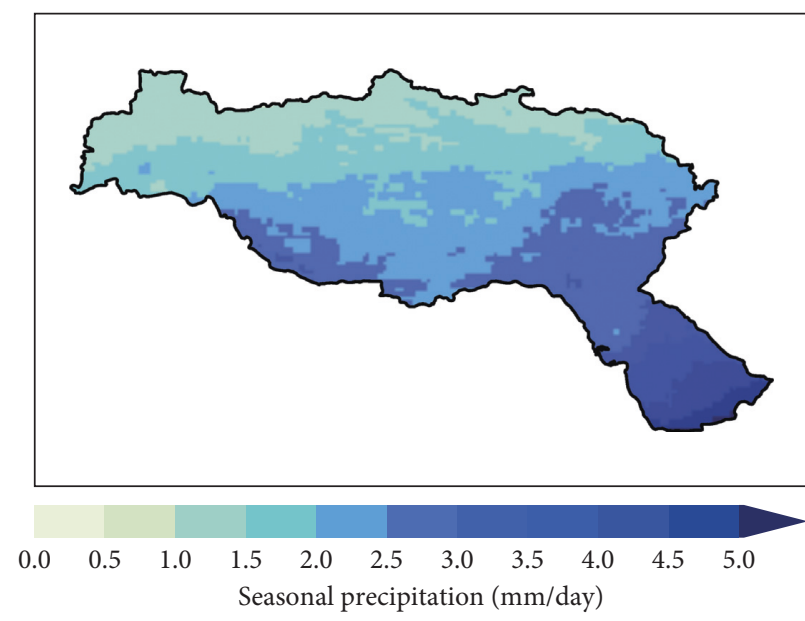

(a)

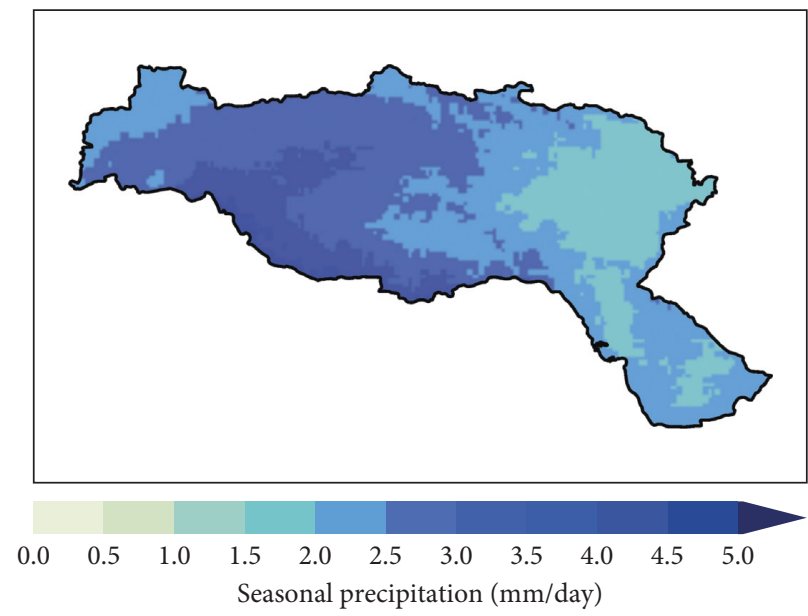

(c)

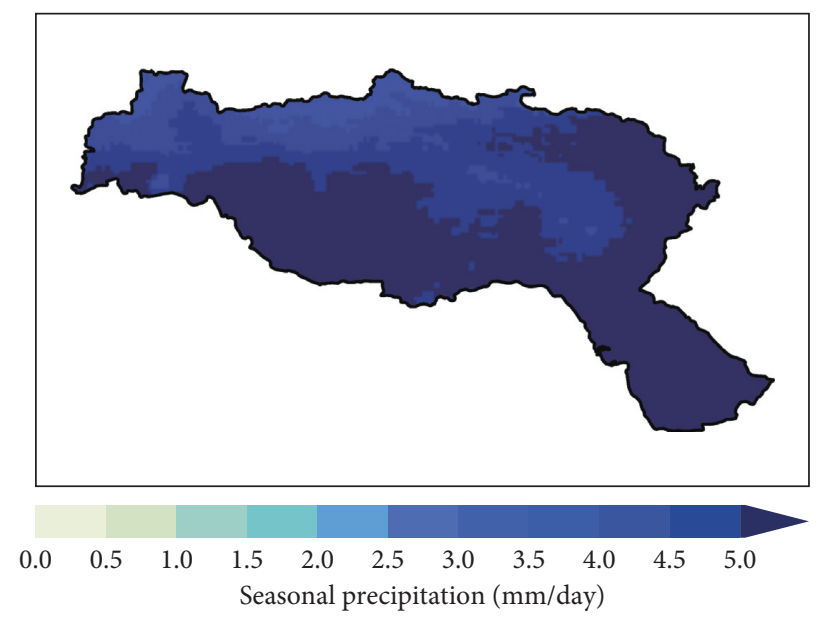

(b)

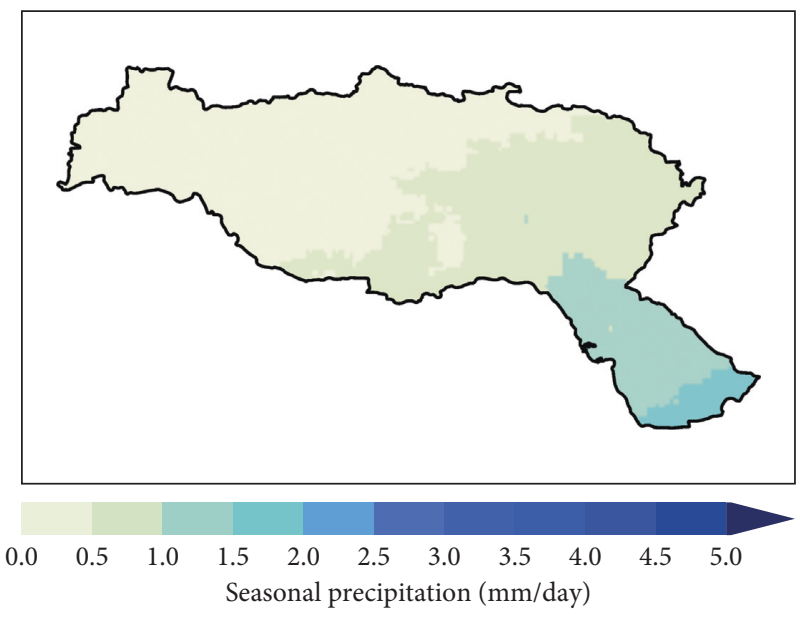

(d)

Figure 2: Spatial patterns of mean seasonal precipitation ( $\mathrm{mm}$ /day) derived from the CHIRPS dataset over the Han River basin for the period of 1981-2010. (a) Spring. (b) Summer. (c) Autumn. (d) Winter.

TABle 1: Areal-averaged seasonal precipitation over the Han River basin.

\begin{tabular}{lc}
\hline Season & Areal-averaged seasonal precipitation $(\mathrm{mm} /$ day $)$ \\
\hline Spring & 2.2 \\
Summer & 5.2 \\
Autumn & 2.4 \\
Winter & 0.6 \\
\hline
\end{tabular}

where integration in the first month was regarded as spin-up time. Thus, forecasts initialized from February 1 for the spring (March-April-May) prediction, May 1 for summer (June-July-August) prediction, August 1 for autumn (September-October-November) prediction, and November 1 for winter (December-January-February) prediction. WRF model version 3.5 provides eleven convective and seven land surface parameterization schemes, each employing different triggers and assumptions, and is therefore suitable for different convective regimes. In this study, four convective schemes and two land surface schemes were combined for each simulation to generate predictions of seasonal precipitation over the Han River basin (Table 2).
The Kain-Fritsch (KF) scheme [30] uses low-level vertical motion as a trigger function and convective available potential energy removal as the closure; thus, it can provide better simulation of the convective processes associated with late afternoon thermodynamic vertical motion induced by heating at the lower boundary [24]. The Betts-Miller-Janjic (BMJ) scheme [31] is an adjustment scheme where the essential principle lies in the relaxation of the temperature and humidity profiles toward reference thermodynamic profiles. The Grell-Freitas (GF) convective parameterization scheme tries to smooth the transition to cloud-resolving scales, as proposed in [32]. The new simplified Arakawa-Schubert (NSAS) scheme is a new mass-flux scheme with deep shallow components and momentum transport. In this scheme, the penetrative convection is simulated, with a saturated downdraft, and the cloud ensemble is reduced to a single cloud type with detrainment only from its top [33].

Research has indicated that the KF convective scheme usually leads to a higher instability for the atmosphere compared with the BMJ and GF schemes over South Africa, which causes a positive bias of precipitation forecasts over 
TABLE 2: Convective and land use parameterization schemes used in downscaling.

\begin{tabular}{lcc}
\hline Combination & Convective parameterization scheme & Land surface process scheme \\
\hline K-N & Kain-Fritsch (KF) & Noah \\
B-N & Betts-Miller-Janjic (BMJ) & Noah \\
G-N & Grell-Freitas (GF) & Noah \\
N-N & New simplified Arakawa-Schubert (NSAS) & Noah \\
K-S & Kain & SSiB \\
B-S & Betts-Miller-Janjic (BMJ) & SSiB \\
G-S & Grell-Freitas (GF) & SSiB \\
N-S & New simplified Arakawa-Schubert (NSAS) & SSiB \\
\hline
\end{tabular}

this region [34]. In comparison, the GF scheme shows better performance on summer precipitation simulations than the $\mathrm{KF}$ and $\mathrm{BMJ}$ convective schemes over China at a horizontal resolution of $60 \mathrm{~km} \mathrm{[35].}$

The Noah land surface model (LSM) was first developed by the Oregon State University (OSU) in the mid-1980s. NCEP continually enhanced the OSU LSM since the 1990s and now renamed the Noah LSM in recognition of the broad partnership with other organizations [36]. It has been widely adopted in global and regional climate models. The simplified Simple Biosphere (SSiB) model is a biophysics-based LSM, which has been coupled with a number of RCMs as well [21]. Both the Noah and SSiB models use explicit vegetation canopy, soil hydrology, and soil thermodynamics. However, the thermodynamic surface energy budget in the Noah model is computed for a single unified ground/vegetation surface without considering the vegetation canopy. In contrast, the surface energy budget in the SSiB model is computed for multiple surfaces representing the ground and additional vegetation canopies. In addition, the Noah model uses four soil layers, while the SSiB model uses three soil layers.

2.3. Evaluation. A high-resolution precipitation dataset, the Climate Hazards Group InfraRed Precipitation with Stations (CHIRPS v2.0), was used to evaluate the added value from the WRF model for the period of 1999-2010 [37]. The CHIRPS was operated by calibrating TRMM satellite data and blending rain gauge observations at a spatial resolution of $0.05^{\circ}$ from 1981 to near present. This dataset has shown good agreement with gauge observations in different regions over the world $[38,39]$. In order to evaluate the seasonal forecasts from different model grids, both the CFS reforecasts and WRF model forecasts were regridded to the CHIRPS $0.05^{\circ}$ grid using a bilinear interpolation method over the Han River basin. The Taylor diagram was used to evaluate the performance of models coupled with different parameterization schemes in terms of correlation, centered root-mean-square (RMS) difference, and standard deviation [40]. The cosine of polar angle is the correlation between forecasts and observations, while the distance from the origin is the forecasted standard deviation. The distance from the reference reflects the RMS difference between forecasts and observations. A higher correlation coefficient, lower RMS difference, and similar standard deviation usually indicate a higher forecast skill.
The anomaly correlation coefficient (ACC) was used to evaluate the forecasted spatial patterns of climatic anomalies [41]:

$$
\mathrm{ACC}=\frac{\sum_{i=1}^{N}\left(F_{i}-\bar{F}\right)\left(O_{i}-\bar{O}\right)}{\sqrt{\sum_{i=1}^{N}\left(F_{i}-\bar{F}\right)^{2}} \sqrt{\sum_{i=1}^{N}\left(O_{i}-\bar{O}\right)^{2}}},
$$

where $F_{i}$ is the forecasted seasonal precipitation, $\bar{F}$ is the multiyear average of seasonal forecasts, $O_{i}$ is the observed seasonal precipitation, and $\bar{O}$ is the multiyear average of observed seasonal precipitation at the grid point $i$. Student's $t$-test was also used to test the significance of the ACC at the 95\% level for both the CFS reforecasts and the WRF model forecasts. As precipitation is always spatially autocorrelated, the effective number of CHIRPS grids was calculated for observed precipitation anomalies in each season and each year before Student's $t$-test.

To understand the causes of the differences in precipitation forecasts using different parameterization schemes, the simulated vertically integrated moisture flux convergence from $1000 \mathrm{hPa}$ to $300 \mathrm{hPa}$, thermodynamic parameters at different pressure levels, convective available potential energy (CAPE), convective inhibition (CIN), and heat fluxes are compared with the data in the ERA-5 reanalysis dataset [42]. ERA-5 is the ECMWF's latest reanalysis product and runs at a high spatial resolution $(30 \mathrm{~km})$ with 137 hybrid vertical sigma/ pressure (model) levels for the atmosphere. Compared with previous reanalysis data, ERA-5 provides several improvements in model physics, numeric algorithms, and data assimilation $[43,44]$.

\section{Results}

The spatial patterns of biases of CFS reforecasts and the WRF model are shown in Figure 3. Positive biases are observed in spring for both CFS reforecasts and the WRF model, ranging from 1 to $3 \mathrm{~mm} /$ day. In particular, the WRF model shows higher positive biases when using the K-N, K-S, and G-S schemes in spring. Compared with those for spring, precipitation forecasts for summer are always negatively biased for CFS reforecasts with a value of -3 to $4 \mathrm{~mm}$ /day. The negative biases of CFS reforecasts are reduced when the WRF model is coupled with K-N and K-S schemes, for which the biases usually range from -2 to $2 \mathrm{~mm}$ /day. Positive biases are always observed in the upper and middle subbasins in autumn, while negative biases are observed in the lower subbasin. The biases of winter precipitation 


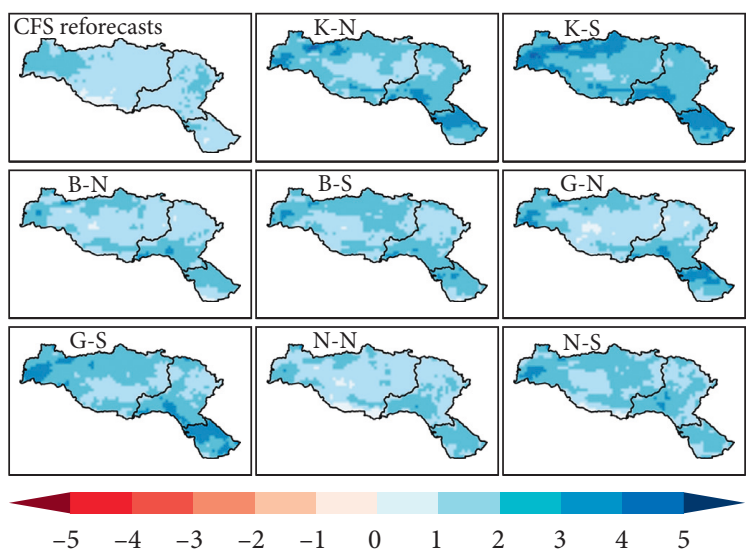

(a)

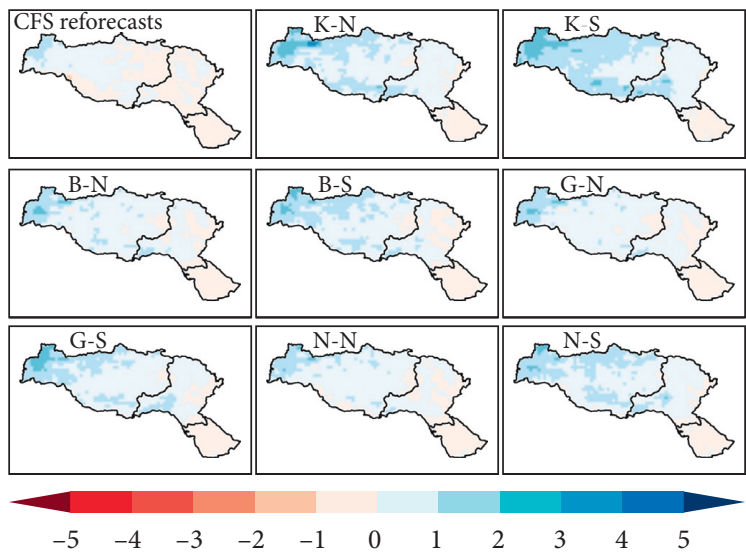

(c)

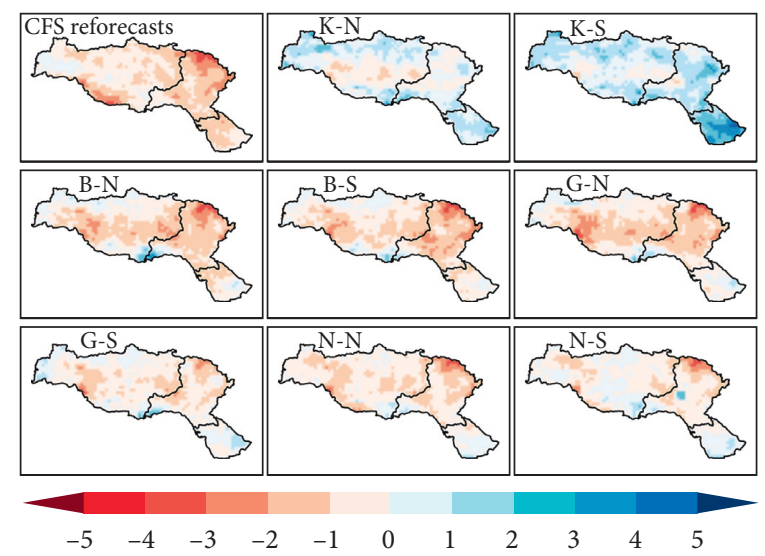

(b)

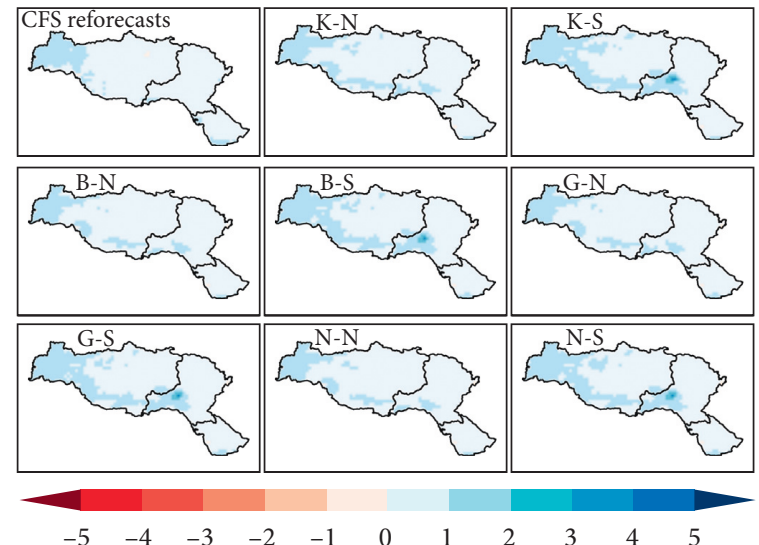

(d)

FIGURE 3: Spatial patterns of biases of CFS reforecasts and the WRF model for the period of 1999-2010 in (a) spring, (b) summer, (c) autumn, and $(\mathrm{d})$ winter ( $\mathrm{mm} /$ day).

forecasts are smaller than those in other seasons, varying from $0.2 \mathrm{~mm} /$ day.

Figure 4 presents the bias of areal-averaged seasonal precipitation forecasts over the Han River basin for the period of 1999-2010. The CFS reforecasts are negatively biased in summer $(-3.4 \mathrm{~mm} /$ day $)$ and autumn $(-1.4 \mathrm{~mm} /$ day). The WRF model shows much lower bias compared with the CFS reforecasts. The bias is $0.0 \mathrm{~mm} /$ day and $0.7 \mathrm{~mm} /$ day when using the $\mathrm{K}-\mathrm{N}$ and $\mathrm{K}-\mathrm{S}$ schemes for summer. However, the bias ranges from -1.8 to $-1.2 \mathrm{~mm} /$ day when using other schemes. In addition, the B-N and B-S schemes are more negatively biased than other schemes. The difference in bias is much smaller for autumn precipitation forecasts with different schemes, and the bias always ranges from -0.3 to $0.0 \mathrm{~mm} /$ day. In contrast, the WRF model is positively biased in spring and winter compared with the CFS reforecasts. The bias of the WRF model always ranges from 1.4 to $2.2 \mathrm{~mm} /$ day in spring, while the bias is from 0.6 to $0.7 \mathrm{~mm} /$ day in winter.

Figure 5 compares the forecast skill of CFS reforecasts and the WRF model using the Taylor diagram. The forecasted seasonal precipitation is always negatively correlated with observations in spring and autumn for all models and schemes. Although the variability of the WRF model forecasts is closer to that of the observations, the RMS differences are greater in the WRF model than in CFS reforecasts in spring. The correlation coefficients usually range from 0.2 to 0.4 for all models and schemes in summer. The RMS differences for the CFS reforecasts and the WRF model are comparable as well, whereas the variability between different models is greater. The standard deviation of forecasts is similar to that of the observations when using the $\mathrm{K}-\mathrm{N}$ scheme. The forecasted precipitation shows lower variability compared with observations when using other schemes. The differences between CFS reforecasts and the WRF model are smaller in winter than in other seasons. Correlation coefficients always range from 0 to 0.4 for all models and schemes, suggesting that the forecast skills are low. Meanwhile, the forecasted variability is also lower than the observation variability in winter.

The anomaly correlation coefficient (ACC) between forecasts and observations is presented in Table 3. The CFS reforecasts show relatively higher skills in 2000, 2004, and 2005 in spring when the spatial patterns of precipitation anomaly are significantly correlated with observations. In contrast, the performance of the WRF model is lower than that of CFS reforecasts in these years. The results of ACC values from the WRF model for summer precipitation 


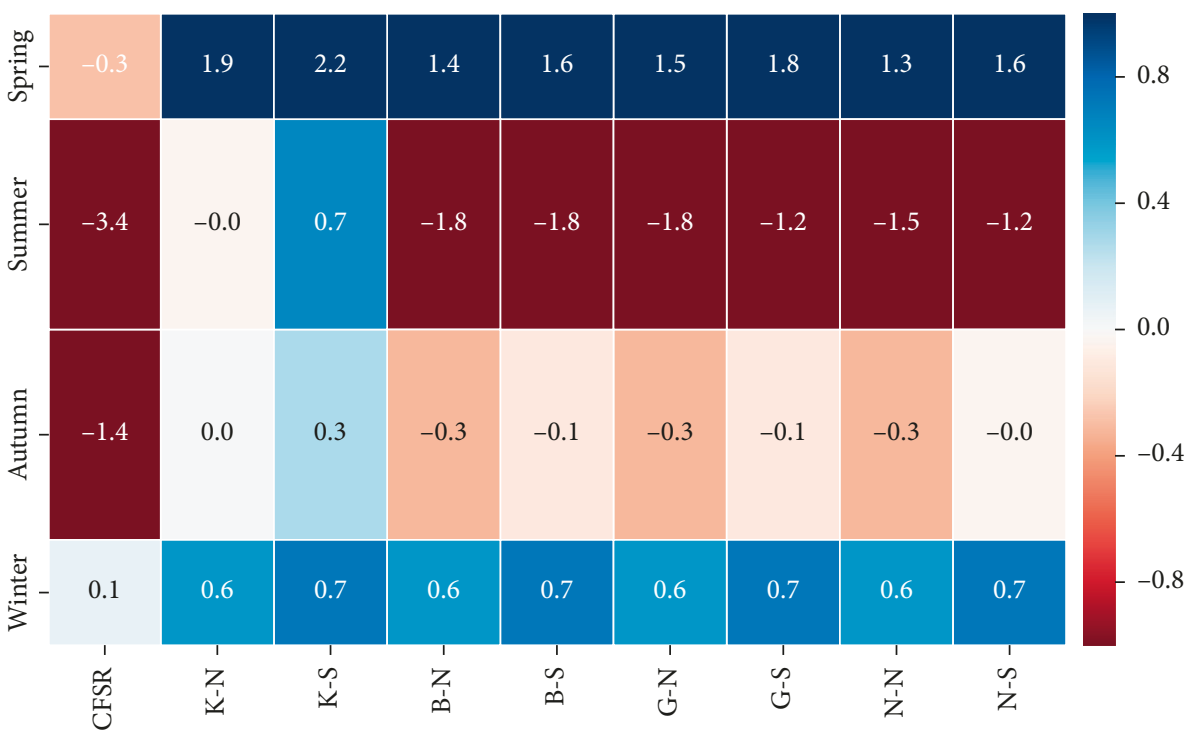

FIGURE 4: Bias of areal-averaged seasonal precipitation forecasts of CFS reforecasts and the WRF model coupled with different convective and land surface parameterization schemes ( $\mathrm{mm} /$ day).

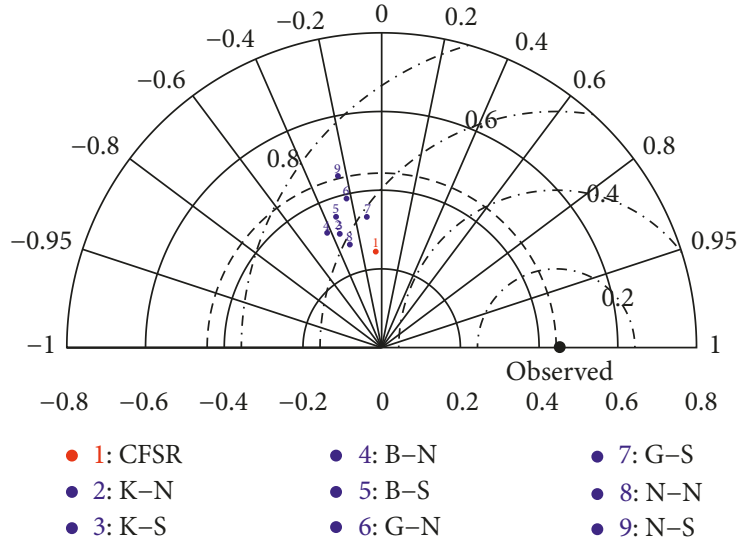

(a)

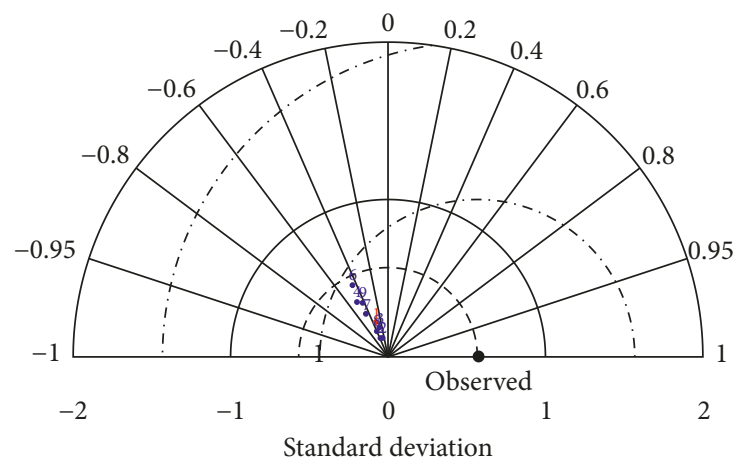

- 1: CFSR

- 2: K-N

- $3: \mathrm{K}-\mathrm{S}$
- 4: B-N
- 5: B-S
- 6: G-N
- 8: N-N
- 9: N-S

(c)

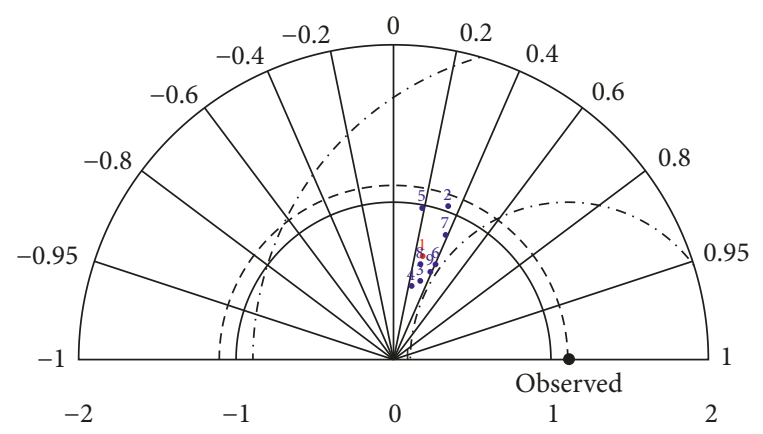

- 1: CFSR

- 2: K-N

- $3: \mathrm{K}-\mathrm{S}$

- 4: B-N

- 5: B-S

- 6: G-N

- 7: G-S

- 8: N-N

(b)

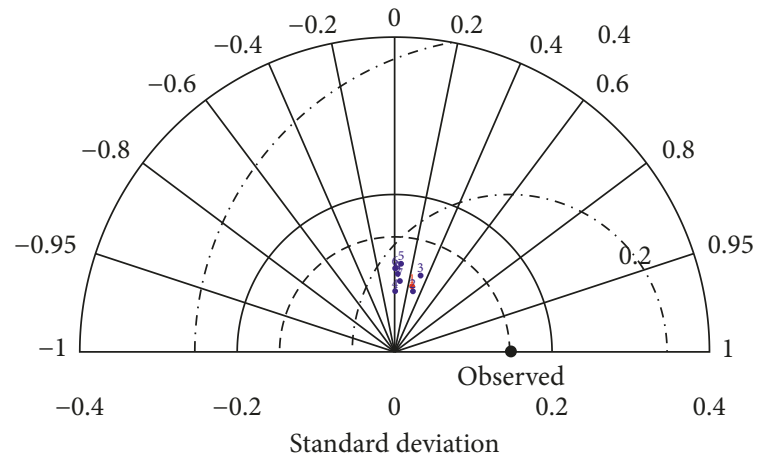

- 4: B-N

7: G-S

- 2: K-N

- $3: \mathrm{K}-\mathrm{S}$

: $\mathrm{B}-\mathrm{S}$

(d)

FIGURE 5: Taylor diagram of the areal-averaged seasonal precipitation forecast skill of CFS reforecasts and the WRF model coupled with different convective and land surface parameterization schemes. (a) Spring. (b) Summer. (c) Autumn. (d) Winter. 
TABLE 3: Anomaly correlation coefficients of seasonal precipitation forecasts from 1999 to 2010.

\begin{tabular}{|c|c|c|c|c|c|c|c|c|c|c|c|c|c|}
\hline & & 1999 & 2000 & 2001 & 2002 & 2003 & 2004 & 2005 & 2006 & 2007 & 2008 & 2009 & 2010 \\
\hline \multirow{9}{*}{ Spring } & CFS & -0.184 & 0.773 & 0.681 & -0.76 & -0.703 & 0.699 & 0.669 & 0.53 & -0.125 & 0.06 & -0.587 & -0.443 \\
\hline & K-N & -0.256 & $-0.293 x$ & $0.13 x$ & -0.242 & -0.272 & $0.016 x$ & 0.446 & -0.279 & 0.052 & $0.21^{*}$ & -0.509 & -0.213 \\
\hline & K-S & -0.405 & $-0.132 x$ & $0.179 x$ & -0.152 & -0.316 & $0.211 x$ & 0.48 & 0.09 & -0.058 & $0.17^{*}$ & -0.492 & -0.058 \\
\hline & $\mathrm{B}-\mathrm{N}$ & -0.109 & $-0.309 x$ & $0.291 x$ & -0.307 & -0.162 & $0.332 x$ & 0.497 & 0.1 & $0.145^{*}$ & $0.163^{*}$ & -0.697 & 0.129 \\
\hline & B-S & -0.178 & $-0.135 x$ & $0.162 x$ & -0.191 & -0.275 & $0.346 x$ & 0.366 & 0.156 & 0.087 & $0.166^{*}$ & -0.423 & 0.281 \\
\hline & G-N & -0.15 & $-0.374 x$ & $0.094 x$ & -0.105 & -0.116 & $0.186 x$ & 0.351 & -0.217 & 0.086 & $0.142^{*}$ & -0.529 & 0 \\
\hline & G-S & -0.263 & $-0.312 x$ & $0.09 x$ & -0.155 & -0.368 & $0.29 x$ & 0.333 & -0.069 & -0.055 & $0.186^{*}$ & -0.501 & 0.382 \\
\hline & $\mathrm{N}-\mathrm{N}$ & -0.173 & $-0.023 x$ & $-0.052 x$ & -0.15 & -0.269 & $0.239 x$ & 0.246 & -0.121 & $0.336^{*}$ & -0.032 & -0.288 & -0.188 \\
\hline & $\mathrm{N}-\mathrm{S}$ & -0.304 & $0.25 x$ & $0.046 x$ & -0.268 & -0.471 & $0.465 x$ & 0.345 & 0.226 & $0.262^{*}$ & 0.036 & -0.307 & -0.222 \\
\hline \multirow{9}{*}{ Summer } & CFS & 0.886 & -0.237 & 0.721 & -0.183 & 0.499 & -0.305 & -0.203 & 0.494 & -0.272 & -0.112 & 0.403 & -0.191 \\
\hline & K-N & $0.403 x$ & -0.117 & $0.361 x$ & 0.098 & 0.586 & 0.111 & 0.272 & 0.371 & $0.318^{*}$ & $0.579^{*}$ & 0.116 & -0.03 \\
\hline & $\mathrm{K}-\mathrm{S}$ & $0.262 x$ & -0.124 & $0.16 x$ & 0.199 & 0.587 & 0.24 & $0.395^{*}$ & 0.364 & $0.366^{*}$ & $0.688^{*}$ & 0.228 & -0.036 \\
\hline & $\mathrm{B}-\mathrm{N}$ & $0.359 x$ & -0.278 & $0.4 x$ & -0.041 & 0.326 & 0.155 & -0.107 & 0.259 & -0.058 & $0.411^{*}$ & -0.03 & -0.151 \\
\hline & B-S & $0.465 x$ & -0.208 & $0.412 x$ & -0.192 & 0.487 & 0.1 & -0.266 & 0.34 & -0.263 & 0.263 & 0.377 & -0.219 \\
\hline & G-N & $0.418 x$ & -0.267 & $0.223 x$ & 0.176 & 0.531 & 0.129 & 0.11 & 0.418 & $0.312^{*}$ & $0.441^{*}$ & $0.522^{*}$ & 0.072 \\
\hline & G-S & $0.382 x$ & -0.166 & $0.389 x$ & 0.123 & 0.519 & 0.224 & 0.25 & 0.476 & $0.303^{*}$ & $0.371^{*}$ & $0.588^{*}$ & 0.105 \\
\hline & $\mathrm{N}-\mathrm{N}$ & $0.388 x$ & 0.056 & 0.443 & -0.05 & 0.491 & 0.132 & 0.25 & 0.451 & $0.283^{*}$ & $0.566^{*}$ & -0.03 & 0.075 \\
\hline & $\mathrm{N}-\mathrm{S}$ & $0.374 x$ & -0.03 & 0.471 & 0.009 & 0.472 & 0.104 & 0.353 & 0.418 & 0.194 & $0.561^{*}$ & -0.017 & -0.067 \\
\hline \multirow{9}{*}{ Autumn } & CFS & -0.052 & -0.316 & 0.275 & 0.184 & 0.113 & -0.032 & -0.425 & 0.212 & 0.39 & 0.168 & -0.199 & 0.087 \\
\hline & K-N & -0.57 & -0.416 & $0.359^{*}$ & -0.211 & 0.416 & $0.744^{*}$ & 0.132 & -0.146 & 0.017 & 0.331 & -0.3 & -0.321 \\
\hline & K-S & -0.533 & -0.451 & $0.381^{*}$ & -0.176 & 0.496 & $0.734^{*}$ & 0.323 & -0.091 & 0 & 0.327 & -0.366 & -0.368 \\
\hline & $\mathrm{B}-\mathrm{N}$ & -0.419 & -0.384 & $0.381^{*}$ & -0.238 & 0.407 & $0.692^{*}$ & 0.244 & -0.155 & 0.121 & 0.296 & -0.478 & -0.369 \\
\hline & B-S & -0.54 & -0.431 & $0.45^{*}$ & -0.255 & 0.467 & $0.77^{*}$ & 0.351 & -0.039 & -0.046 & 0.297 & -0.488 & -0.2 \\
\hline & G-N & -0.595 & -0.33 & $0.397^{*}$ & -0.004 & 0.391 & $0.723^{*}$ & 0.206 & -0.129 & 0.136 & 0.216 & -0.44 & -0.2 \\
\hline & G-S & -0.474 & -0.394 & $0.445^{*}$ & -0.096 & 0.46 & $0.673^{*}$ & 0.31 & -0.041 & 0.049 & 0.255 & -0.44 & -0.212 \\
\hline & $\mathrm{N}-\mathrm{N}$ & -0.572 & -0.401 & $0.402^{*}$ & 0.045 & 0.425 & $0.699^{*}$ & 0.119 & -0.284 & 0.206 & 0.394 & -0.278 & -0.227 \\
\hline & $\mathrm{N}-\mathrm{S}$ & -0.464 & -0.423 & $0.382^{*}$ & 0.008 & 0.484 & 0.505 & 0.244 & -0.248 & 0.075 & 0.387 & -0.271 & -0.219 \\
\hline \multirow{9}{*}{ Winter } & CFS & 0.884 & 0.78 & -0.669 & -0.448 & -0.211 & 0.142 & -0.34 & 0.177 & -0 . & 0.394 & 0.565 & 0.806 \\
\hline & K-N & $0.554 x$ & 0.702 & -0.548 & -0.405 & -0.119 & 0.059 & -0.267 & 0.252 & -0.522 & 0.088 & 0.441 & 0.714 \\
\hline & $\mathrm{K}-\mathrm{S}$ & $0.544 x$ & 0.688 & -0.4 & -0.408 & -0.138 & 0.152 & -0.315 & 0.234 & -0.524 & 0.129 & 0.336 & 0.653 \\
\hline & B-N & $0.459 x$ & 0.677 & -0.572 & -0.434 & -0.073 & 0.069 & -0.166 & 0.225 & -0.524 & 0.055 & 0.49 & 0.716 \\
\hline & B-S & $0.485 x$ & 0.672 & -0.424 & -0.438 & -0.111 & 0.148 & -0.193 & 0.238 & -0.526 & 0.118 & 0.36 & 0.655 \\
\hline & G-N & $0.435 x$ & 0.66 & -0.579 & -0.405 & -0.097 & 0.067 & -0.166 & 0.233 & -0.471 & 0.015 & 0.494 & 0.686 \\
\hline & G-S & $0.481 x$ & 0.643 & -0.44 & -0.422 & -0.126 & 0.138 & -0.209 & 0.248 & -0.467 & 0.072 & 0.36 & 0.623 \\
\hline & $\mathrm{N}-\mathrm{N}$ & $0.456 x$ & 0.709 & -0.57 & -0.407 & -0.094 & 0.073 & -0.256 & 0.229 & -0.528 & 0.041 & 0.483 & 0.735 \\
\hline & $\mathrm{N}-\mathrm{S}$ & $0.471 x$ & 0.7 & -0.438 & -0.42 & -0.119 & 0.138 & -0.265 & 0.226 & -0.519 & 0.094 & 0.385 & 0.668 \\
\hline
\end{tabular}

Statistically significant correlations at the $95 \%$ level are in bold shading. For WRF seasonal forecasts, an asterisk indicates that the result is statistically significant and better than the CFS reforecasts; bold indicates that the WRF seasonal forecasts are worse than the CFS reforecasts and statistical significance is retained; $\mathrm{x}$ indicates that the WRF seasonal forecasts are worse than the CFS reforecasts and statistical significance is lost.

forecasts are higher than those of the CFS reforecasts except for 1999, 2001, 2006, and 2009 where the K-N and K-S schemes are used, suggesting that the WRF model can add values compared with CFS reforecasts in some cases. The ACC values of the WRF model are also higher than those of the CFS reforecasts when using the G-S scheme in summer except for 1999, 2001, and 2006. We should also notice that the B-S scheme shows lowest forecast skills compared with other schemes in summer, in which the forecasts are not significantly correlated with the observations for all years. The forecast skills are significantly improved after using the WRF model in 2001 and 2004 for autumn precipitation forecasts. Compared with other seasons, the WRF model has lower ACC values than the CFS reforecasts in most of the years in winter, indicating that the performance of the CFS reforecasts is better than that of the WRF model.

In order to find the reasons for bias of precipitation forecasts in each season, the moisture flux convergence is analysed by vertically integrating from $1000 \mathrm{hPa}$ to $300 \mathrm{hPa}$.
Strong moisture flux convergence is observed over the southern Han River basin in the ERA-5 reanalysis in spring, while strong moisture divergence is observed in the northwestern Han River basin (Figure 6). In contrast, both the CFS reforecasts and the WRF model show moisture flux convergence over the Han River basin. In addition, the moisture flux convergence of the WRF model is stronger than that of both the ERA-5 reanalysis and the CFS reforecasts. The spatial patterns of moisture flux convergence in summer are similar to those in spring. Both the CFS reforecasts and the WRF model underestimate the moisture flux convergence compared with ERA-5 reanalysis, which explains the negative biases observed in summer precipitation forecasts. Strong moisture flux convergence is observed in the lower subbasin in autumn. On the contrary, the spatial patterns of the moisture flux convergence of the CFS reforecasts and the WRF model are opposite to those of the ERA-5 reanalysis. The spatial patterns of moisture flux convergence of the CFS reforecasts and the WRF model are 


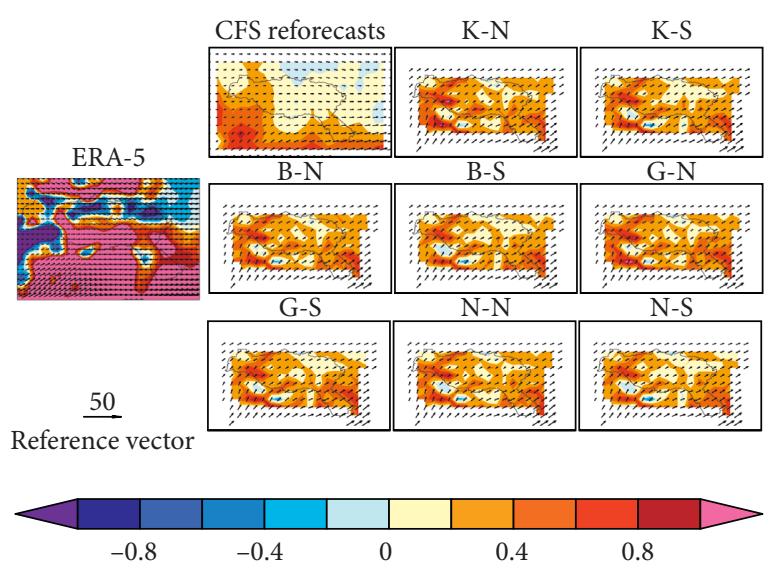

(a)

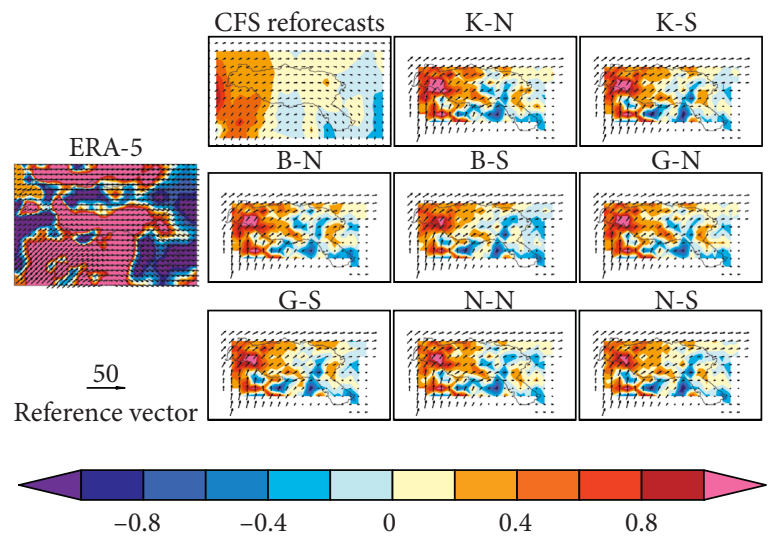

(c)
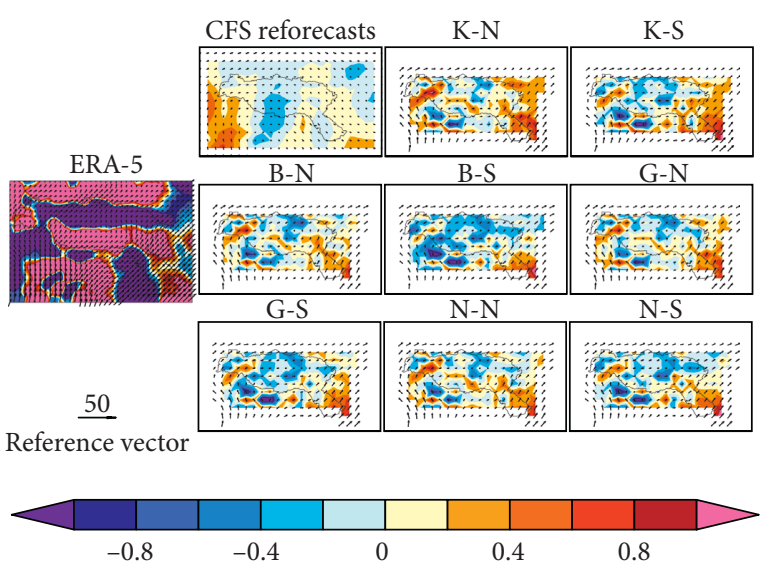

(b)
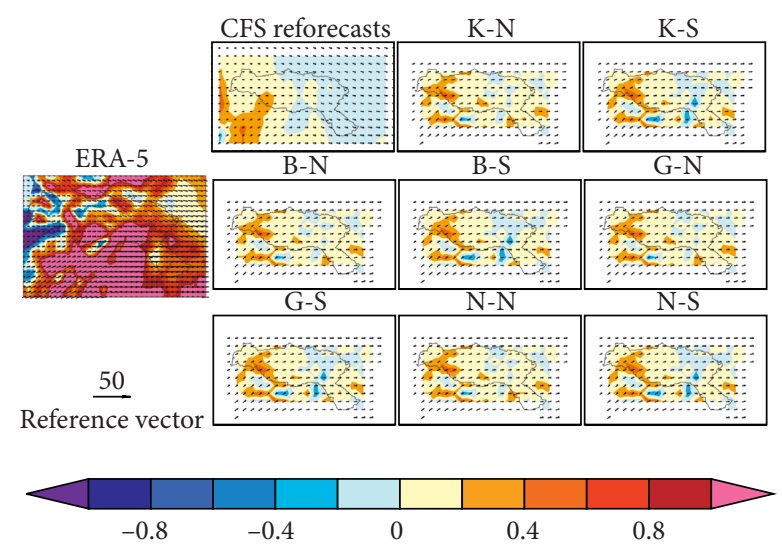

(d)

FIgURE 6: Spatial patterns of vertically integrated (from 1,000 to $300 \mathrm{hPa}$ ) moisture fluxes $\left(100 \mathrm{~g} / \mathrm{cm} \mathrm{s}^{-1}\right.$ ) (arrows) and moisture flux convergence (multiplied by $10^{-5} \mathrm{~s}^{-1}$ ) (shaded areas) of ERA-5 reanalysis, CFS reforecasts, and the WRF model in (a) spring, (b) summer, (c) autumn, and (d) winter.

similar to those of the ERA-5 reanalysis in the middle and lower subbasins in winter. However, the magnitude of convergence of CFS reforecasts and the WRF model is much lower than that of ERA-5 reanalysis.

To further explore possible reasons for the differences in precipitation forecasts, biases of thermodynamical characteristics at different vertical pressure levels are analysed by comparing the results with ERA- 5 reanalysis results in Figure 7 . The vertical velocity is always overestimated in spring and autumn for all models and all schemes. However, the biases of vertical velocity for CFS reforecasts are smaller than those of the WRF model. On the contrary, the vertical velocity is always underestimated in summer, indicating a more stable atmosphere compared with that in ERA-5 reanalysis. The biases of K-N and K-S schemes are much smaller than those of CFS reforecasts and other schemes. Although the B-S scheme shows lower biases compared with the CFSv2 reforecasts, they are higher negative biases compared with those of other schemes. The vertical velocity shows no differences between different parameterization schemes in winter. When considering the vertical moisture profile, it is seen that the CFS reforecasts and the WRF model are always negatively biased in spring and summer. The Noah land surface scheme is more negatively biased than the SSiB scheme between low and middle pressure levels, suggesting that the Noah scheme leads to drier vertical conditions. In comparison, the WRF model is positively biased for all pressure levels from $850 \mathrm{hPa}$ to $500 \mathrm{hPa}$ in autumn and winter. The equivalent potential temperature is used to indicate the stability of the vertical profile. Positive biases of equivalent potential temperature are observed at lower pressure levels for all seasons, suggesting that both the CFSv2 reforecasts and the WRF model are more stable than observed ones. In particular, the WRF model simulated a more stable atmosphere than the CFSv2 reforecasts in autumn and winter at lower pressure levels. In contrast, the CFSv2 reforecasts and the WRF model simulated a more unstable atmosphere at higher pressure levels. We should also notice that the differences in equivalent potential temperature between different convective parameterization and land surface scheme combinations are small. This suggests that other parameterization schemes, such as the planetary boundary layer scheme, should be further investigated over this region to improve the simulation of equivalent potential temperature. 


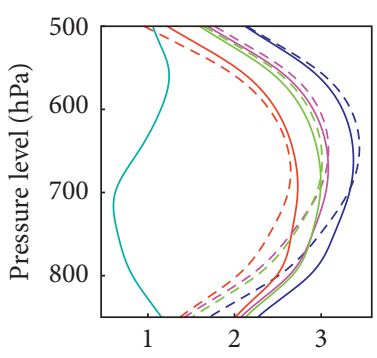

Vertical velocity $\left(10^{-3} \mathrm{~m} / \mathrm{s}\right)$
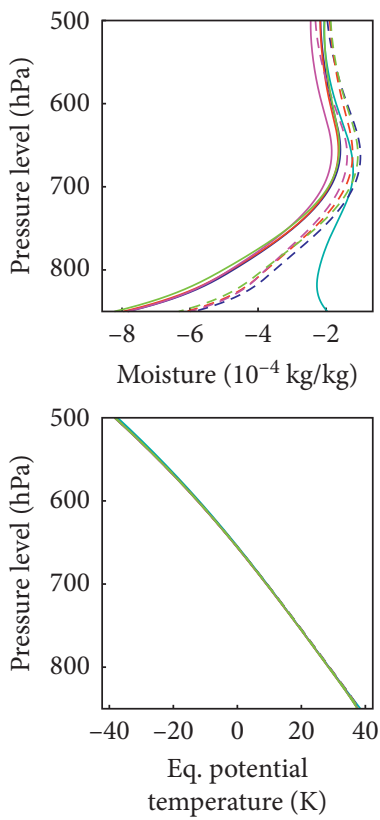

C CFS reforecasts
- K-N
--- K-S
- B-N
--- B-S
- G-N
--- G-S
- N-N
--- N-S

(a)

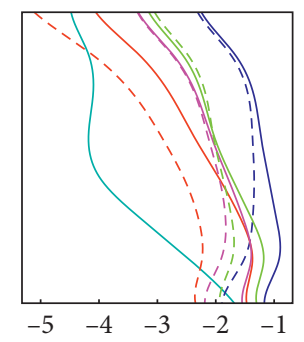

Vertical velocity $\left(10^{-3} \mathrm{~m} / \mathrm{s}\right)$
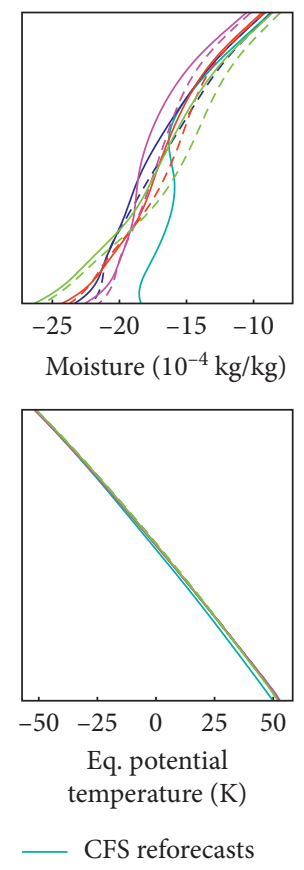

- K-N

- - - K-S

- B-N

- $-\mathrm{B}-\mathrm{S}$

- G-N

- - G-S

N-N

-.- N-S

(b)

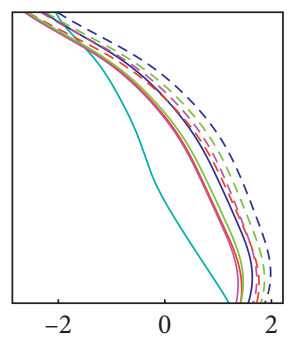

Vertical velocity $\left(10^{-3} \mathrm{~m} / \mathrm{s}\right)$

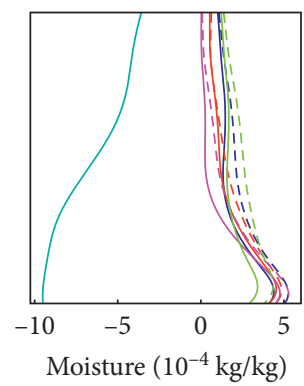

Vertical velocity $\left(10^{-3} \mathrm{~m} / \mathrm{s}\right)$
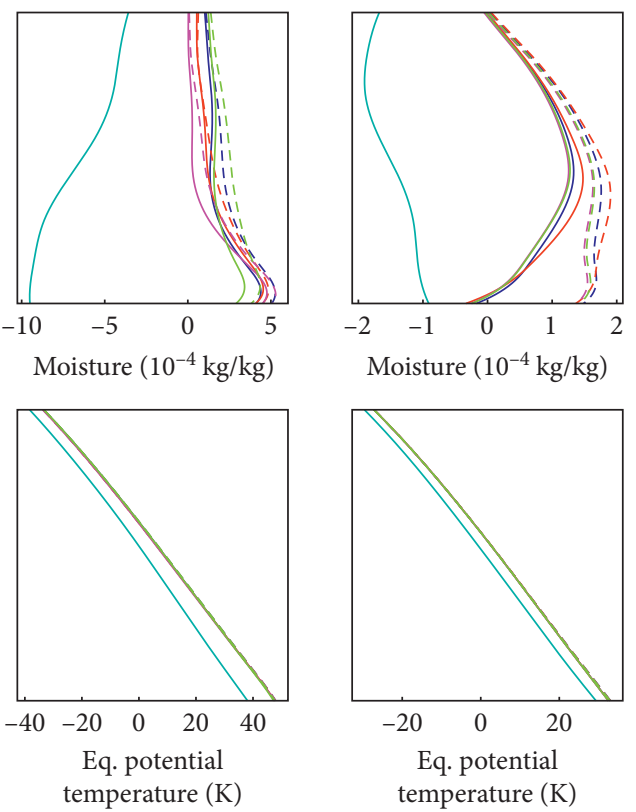

temperature $(\mathrm{K})$

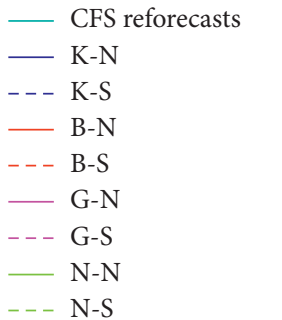

(c)

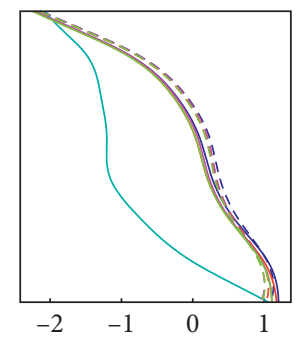




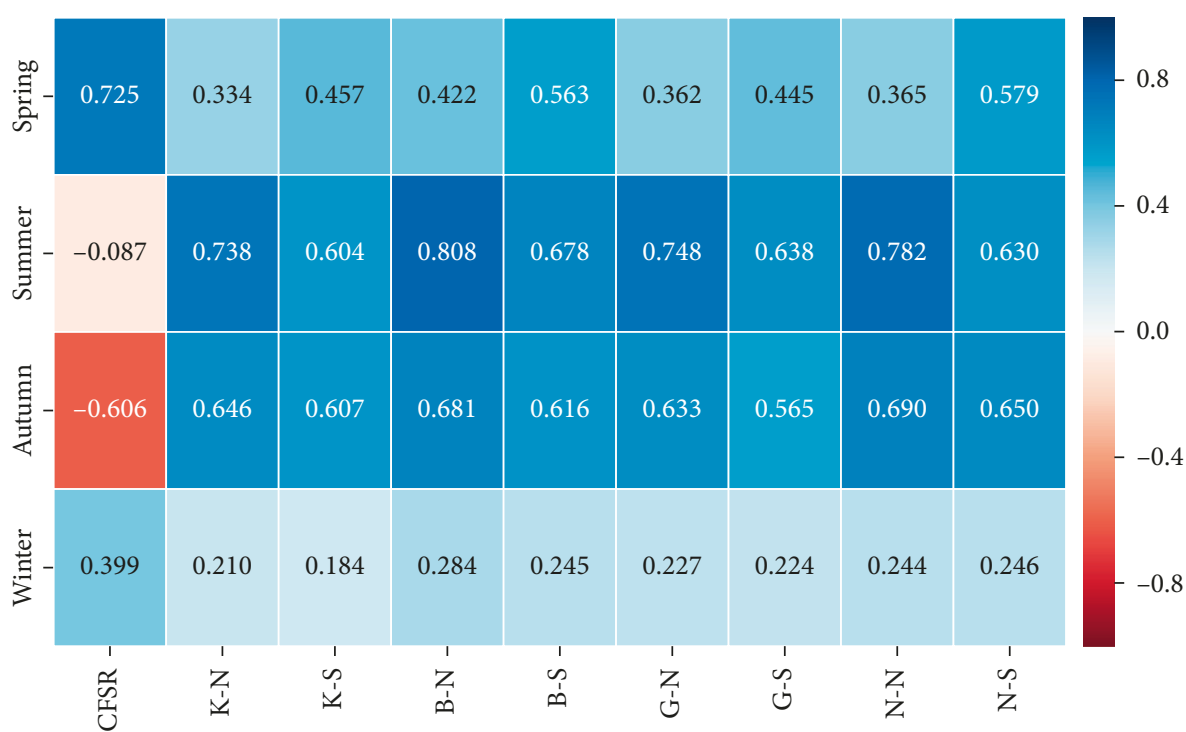

FIGURE 8: Pattern correlations of convective available potential energy between CFS reforecasts, the WRF model, and ERA-5 reanalysis for the period of $1999-2010$.

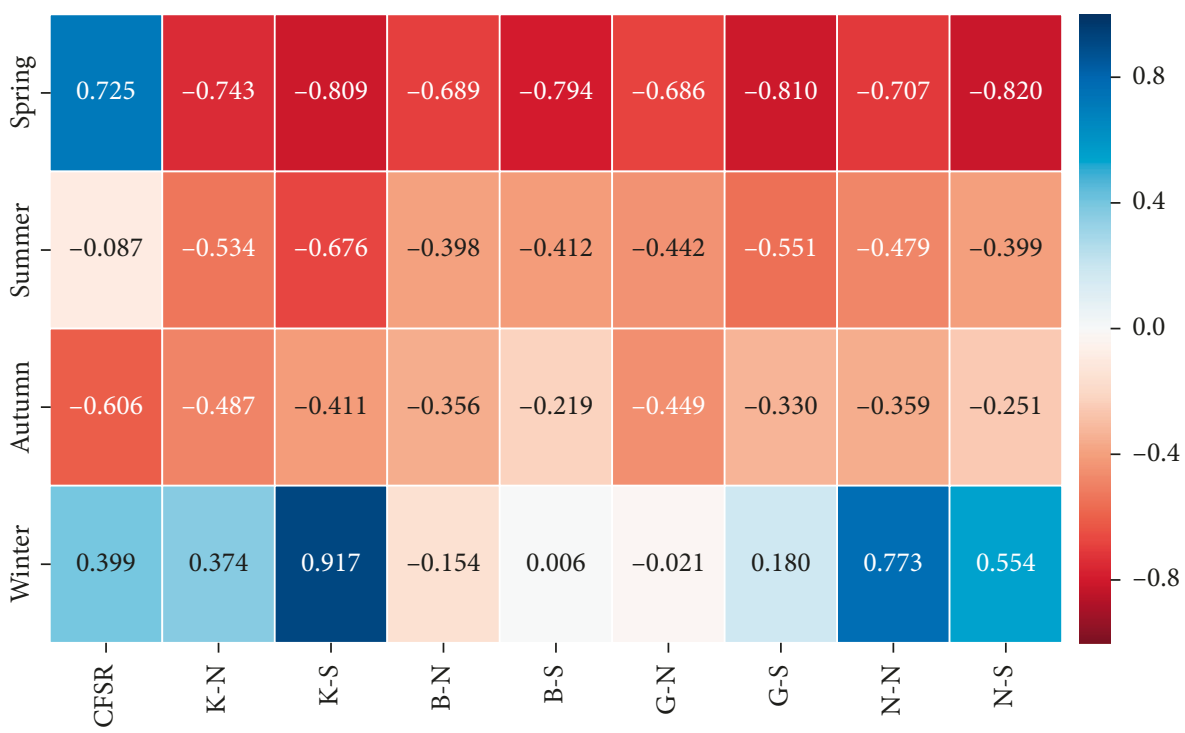

FIgURE 9: The same as Figure 8, but for convective inhibition energy.

correlated with the ERA-5 reanalysis (Figure 9). However, spatial patterns of CIN of the WRF model are opposite to those of the ERA-5 reanalysis and CFSv2 reforecasts in spring. Negative spatial pattern correlations are observed no matter what convective and land surface schemes are used. This is also observed in summer and autumn, where the spatial patterns of CIN of the WRF model are negatively correlated with those of the ERA-5 reanalysis. The spatial patterns of CIN are improved compared with those of the CFSv2 reforecasts when using the K-S, N-N, and N-S schemes in winter.

The sensible and latent heat fluxes are analysed to investigate the influence of the land surface scheme on seasonal precipitation forecasts. As shown in Figures 10 and 11, the spatial patterns of sensible heat fluxes and latent heat fluxes of the CFSv2 reforecasts are positively correlated with those of the ERA-5 reanalysis in spring. On the contrary, the WRF model shows much lower agreement between forecasts and observations compared with the CFSv2 reforecasts. The spatial patterns of sensible heat fluxes and latent heat fluxes are improved when the WRF model is used in summer. The pattern correlations of different schemes are almost the same for sensible heat fluxes, while greater diversity is observed for latent heat fluxes. The K-S and G-S schemes show better agreement with the ERA-5 reanalysis compared with other schemes. In autumn, the WRF model improves the simulation of sensible heat fluxes, while the latent heat fluxes are worsened compared with CFSv2 reforecasts. The spatial patterns of sensible heat fluxes and latent heat fluxes of the CFSv2 reforecasts are better in 


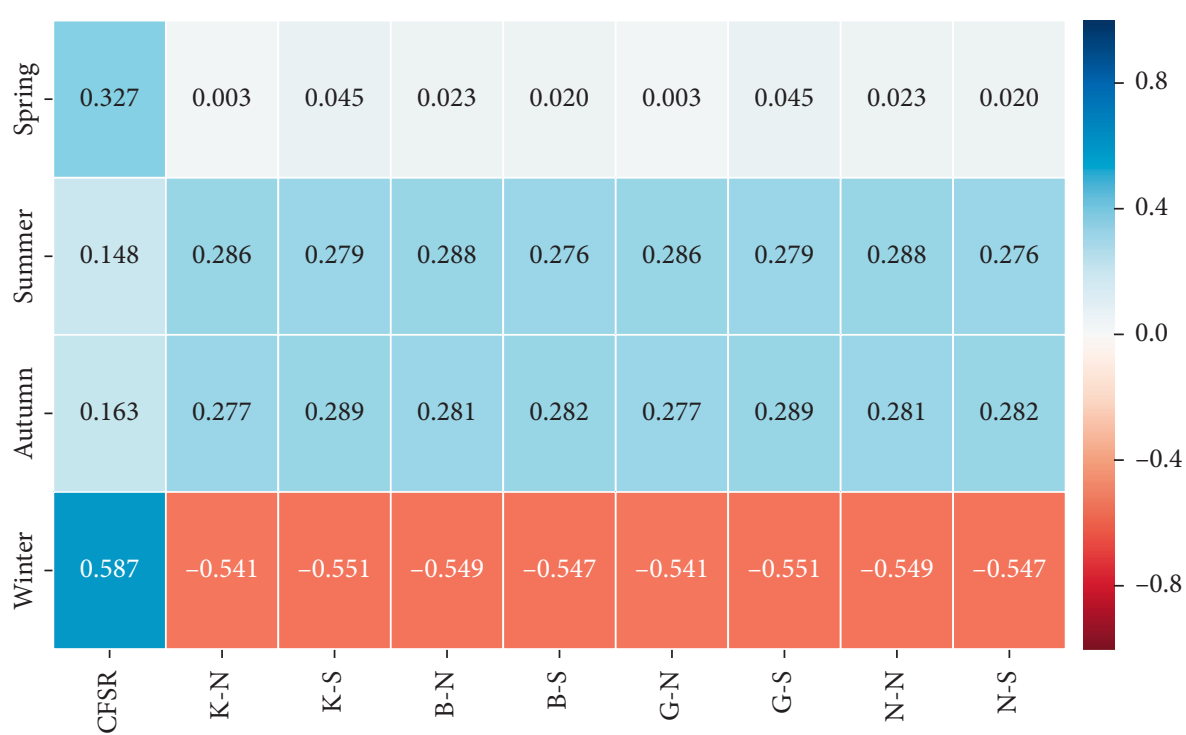

FIGURE 10: Pattern correlations of sensible heat fluxes between CFS reforecasts, the WRF model, and ERA-5 reanalysis for the period of 1999-2010.

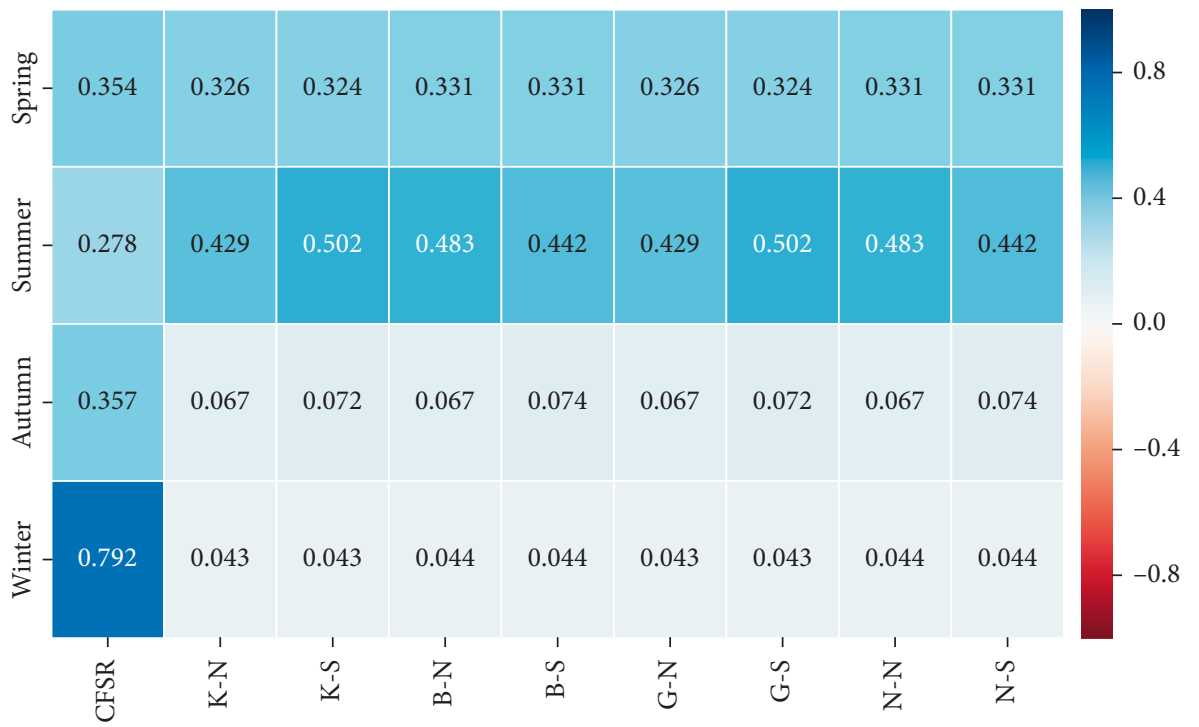

FIgURE 11: The same as Figure 10, but for latent heat fluxes.

consistent with those of ERA-5 reanalysis than those of the WRF model in winter.

\section{Conclusions}

This study investigates the sensitivity of dynamical downscaling seasonal precipitation forecasts to convective and land surface parameterization schemes by nesting the WRF model at $10 \mathrm{~km}$ horizontal resolution into CFSv2 reforecasts. It is found that the CFS reforecasts are always positively biased in spring, autumn, and winter, while the CFS reforecasts are negatively biased in summer. The WRF model reduces the negative biases of precipitation forecasts when $\mathrm{K}-\mathrm{N}$ and $\mathrm{K}-\mathrm{S}$ schemes are used in summer. However, negative biases still exist when other parameterization schemes are used, especially for the B-N and B-S schemes.
The Taylor diagram and the anomaly correlation coefficient suggest that the forecast skill of the $\mathrm{K}-\mathrm{N}$ scheme is better than that of the CFS reforecasts in summer in some cases, while the forecast skill of the B-S scheme is worse than that of any other parameterization schemes. The differences between the performance of the CFS reforecasts and the WRF model are smaller in other seasons.

To understand the causes of the differences in precipitation forecasts using different parameterization schemes, we also compare the integrated moisture flux convergence, thermodynamic parameters at different pressure levels, convective available potential energy (CAPE), convective inhibition (CIN), and heat fluxes with the data in the ERA-5 reanalysis dataset. Both the CFS reforecasts and the WRF model underestimate the moisture flux convergence compared with ERA-5 reanalysis, which partly 
explains the negative biases observed in summer precipitation forecasts. In addition, the differences in moisture flux convergence between different parameterization schemes are small. The biases of K-N and K-S schemes of vertical velocity are much smaller than those of CFS reforecasts and other parameterization schemes, suggesting a more unstable atmosphere in summer, which is crucial for precipitation. In contrast, the B-S scheme shows higher negative biases compared with other schemes, indicating a less convective unstable environment. This explains the relatively lower forecast skills when using the B-S scheme in summer. The WRF model also improves the spatial patterns of CAPE in summer, which further enhances the precipitation forecast skills over the Han River basin.

This study only investigates the influence of convective and land surface parameterization schemes on dynamical downscaling precipitation forecasts. However, other factors including scales, boundary condition treatment, microphysics parameterization schemes, planetary boundary parameterization schemes, and other regional climate models may influence the precipitation forecasts as well. Sensitivity tests on these factors will be considered in a future study.

\section{Data Availability}

The CHIRPS v2.0 and CFSv2 reforecast data used to support the findings of this study are included within the article.

\section{Conflicts of Interest}

The authors declare that there are no conflicts of interest regarding the publication of this paper.

\section{Acknowledgments}

This work was funded by the National Key R\&D Program of China (Grant no. 2018YFC0407701 and 2017YFC1502403), the National Natural Science Foundation of China (Grant no. 51579065 and 51779071), the Fundamental Research Funds for the Central Universities (Grant no. 2017B10514 and 2017B681X14), and the Postgraduate Research \& Practice Innovation Program of Jiangsu Province (Grant no. KYCX17_0413).

\section{References}

[1] B. P. Kirtman, D. Min, J. M. Infanti et al., "The North American multimodel ensemble: phase-1 seasonal-to-interannual prediction; phase-2 toward developing intraseasonal prediction," Bulletin of the American Meteorological Society, vol. 95, no. 4, pp. 585-601, 2014.

[2] H. Wang and K. Fan, "A new scheme for improving the seasonal prediction of summer precipitation anomalies," Weather and Forecasting, vol. 24, no. 2, pp. 548-554, 2009.

[3] D. L. Feldman and H. M. Ingram, "Making science useful to decision makers: climate forecasts, water management, and knowledge networks," Weather, Climate, and Society, vol. 1, no. 1, pp. 9-21, 2009.

[4] S. Saha, S. Moorthi, X. Wu et al., "The NCEP climate forecast system version 2," Journal of Climate, vol. 27, no. 6, pp. 2185-2208, 2014.
[5] H.-M. Kim, P. J. Webster, and J. A. Curry, "Seasonal prediction skill of ECMWF system 4 and NCEP CFSv2 retrospective forecast for the northern hemisphere winter," Climate Dynamics, vol. 39, no. 12, pp. 2957-2973, 2012.

[6] H. A. Rashid, H. H. Hendon, M. C. Wheeler, and O. Alves, "Prediction of the Madden-Julian oscillation with the POAMA dynamical prediction system," Climate Dynamics, vol. 36 , no. 3-4, pp. 649-661, 2011.

[7] National Research Council, Assessment of Intraseasonal to Interannual Climate Prediction and Predictability, National Academies Press, Washington, DC, USA, 2010.

[8] B. Kirtman and A. Pirani, "WCRP position paper on seasonal prediction," Report from the First WCRP Seasonal Prediction Workshop, 4-7 June 2007. Technical report, WCRP Informal Report No. 3/2008, ICPO Publication, Barcelona, Spain, 2008.

[9] E. K. Jin, J. L. Kinter, B. Wang et al., "Current status of ENSO prediction skill in coupled ocean-atmosphere models," Climate Dynamics, vol. 31, no. 6, pp. 647-664, 2008.

[10] T. Stocker, "Climate change 2013: the physical science basis," Working Group I Contribution to the Fifth Assessment Report of the Intergovernmental Panel on Climate Change, Cambridge University Press, Cambridge, UK, 2014.

[11] T. M. Lenton, H. Held, E. Kriegler et al., "Tipping elements in the Earth's climate system," Proceedings of the National Academy of Sciences, vol. 105, no. 6, pp. 1786-1793, 2008.

[12] T. C. Bond, S. J. Doherty, D. W. Fahey et al., "Bounding the role of black carbon in the climate system: a scientific assessment," Journal of Geophysical Research: Atmospheres, vol. 118, no. 11, pp. 5380-5552, 2013.

[13] X. Yuan, E. F. Wood, L. Luo et al., "A first look at Climate Forecast System version 2 (CFSv2) for hydrological seasonal prediction," Geophysical Research Letters, vol. 38, no. 13, 2011.

[14] S. Pokhrel, S. K. Saha, A. Dhakate et al., "Seasonal prediction of Indian summer monsoon rainfall in NCEP CFSv2: forecast and predictability error," Climate Dynamics, vol. 46, no. 7-8, pp. 2305-2326, 2016.

[15] H.-M. Kim, P. J. Webster, J. A. Curry, and V. E. Toma, “Asian summer monsoon prediction in ECMWF system 4 and NCEP CFSv2 retrospective seasonal forecasts," Climate Dynamics, vol. 39, no. 12, pp. 2975-2991, 2012.

[16] D. S. Gutzler, H.-K. Kim, R. W. Higgins et al., "The North American monsoon model assessment Project: integrating numerical modeling into a field-based process study," Bulletin of the American Meteorological Society, vol. 86, no. 10, pp. 1423-1430, 2005.

[17] C. L. Castro, R. A. Pielke Sr., and J. O. Adegoke, "Investigation of the summer climate of the contiguous United States and Mexico using the regional atmospheric modeling system (RAMS). Part I: model climatology (1950-2002)," Journal of Climate, vol. 20, no. 15, pp. 3844-3865, 2007.

[18] F. Feser, B. Rockel, H. von Storch et al., "Regional climate models add value to global model data: a review and selected examples," Bulletin of the American Meteorological Society, vol. 92, no. 9, pp. 1181-1192, 2011.

[19] X.-Z. Liang, L. Li, K. E. Kunkel, M. Ting, and J. X. L. Wang, "Regional climate model simulation of U.S. precipitation during 1982-2002. part I: annual cycle," Journal of Climate, vol. 17, no. 18, pp. 3510-3529, 2004.

[20] B. Yang, Y. Qian, G. Lin et al., "Some issues in uncertainty quantification and parameter tuning: a case study of convective parameterization scheme in the WRF regional climate model," Atmospheric Chemistry \& Physics, vol. 12, no. 5, 2012.

[21] Y. Xue, F. J. Zeng, K. E. Mitchell, Z. Janjic, and E. Rogers, “The impact of land surface processes on simulations of the U.S. 
hydrological cycle: a case study of the 1993 flood using the SSiB land surface model in the NCEP Eta regional model," Monthly Weather Review, vol. 129, no. 12, pp. 2833-2860, 2001.

[22] R. de Elía, D. Caya, H. Côté et al., "Evaluation of uncertainties in the CRCM-simulated North American climate," Climate Dynamics, vol. 30, no. 2-3, pp. 113-132, 2008.

[23] J. Crétat, B. Pohl, Y. Richard, and P. Drobinski, "Uncertainties in simulating regional climate of Southern Africa: sensitivity to physical parameterizations using WRF," Climate Dynamics, vol. 38, no. 3-4, pp. 613-634, 2012.

[24] L. Pei, N. Moore, S. Zhong et al., "WRF model sensitivity to land surface model and cumulus parameterization under short-term climate extremes over the southern great plains of the United States," Journal of Climate, vol. 27, no. 20, pp. 7703-7724, 2014.

[25] Y. Li, G. Lu, Z. Wu, H. He, and J. He, "High-resolution dynamical downscaling of seasonal precipitation forecasts for the Hanjiang basin in China using the weather research and forecasting model," Journal of Applied Meteorology and Climatology, vol. 56, no. 5, pp. 1515-1536, 2017.

[26] R. D. Koster, P. A. Dirmeyer, Z. Guo et al., "Regions of strong coupling between soil moisture and precipitation," Science, vol. 305, no. 5687, pp. 1138-1140, 2004.

[27] S. Y. Hong, Y. Noh, and J. Dudhia, "A new vertical diffusion package with an explicit treatment of entrainment processes," Monthly Weather Review, vol. 134, no. 9, pp. 2318-2341, 2004.

[28] J. Dudhia, "Numerical study of convection observed during the winter monsoon experiment using a mesoscale two-dimensional model," Journal of the Atmospheric Sciences, vol. 46, no. 20, pp. 3077-3107, 1989.

[29] E. J. Mlawer, S. J. Taubman, P. D. Brown, M. J. Iacono, and S. A. Clough, "Radiative transfer for inhomogeneous atmospheres: RRTM, a validated correlated-k model for the longwave," Journal of Geophysical Research: Atmospheres, vol. 102, no. 14, pp. 16663-16682, 1997.

[30] J. S. Kain, "The Kain-Fritsch convective parameterization: an update," Journal of Applied Meteorology, vol. 43, no. 1, pp. 170-181, 2004.

[31] Z. I. Janjic', "Comments on "Development and evaluation of a convection scheme for use in climate models," Journal of the Atmospheric Sciences, vol. 57, p. 3686, 2000.

[32] S. R. Freitas, G. Grell, A. Molod et al., "The Grell-Freitas convection parameterization: recent developments and applications within the NASA GEOS global model," in Proceedings of the Annual American Geophysical Union (AGU) Fall Meeting Abstracts, San Francisco, CA, USA, 2017.

[33] T. N. Krishnamurti and J. Sanjay, "A new approach to the cumulus parameterization issue," Tellus A, vol. 55, no. 4, pp. 275-300, 2003.

[34] S. B. Ratna, J. V. Ratnam, S. K. Behera et al., "Performance assessment of three convective parameterization schemes in WRF for downscaling summer rainfall over South Africa," Climate Dynamics, vol. 42, no. 11-12, pp. 2931-2953, 2014.

[35] E. Yu, H. Wang, Y. Gao, and J. Sun, "Impacts of cumulus convective parameterization schemes on summer monsoon precipitation simulation over China," Acta Meteorologica Sinica, vol. 25, no. 5, pp. 581-592, 2011.

[36] F. Chen and J. Dudhia, "Coupling an advanced land surfacehydrology model with the penn state-NCAR MM5 modeling system. Part I: model implementation and sensitivity," Monthly Weather Review, vol. 129, no. 4, pp. 569-585, 2001.
[37] C. Funk, P. Peterson, M. Landsfeld et al., "The climate hazards infrared precipitation with stations-a new environmental record for monitoring extremes," Scientific Data, vol. 2, 2015.

[38] K. Dimitrios and R. Adrianos, "Analysis of precipitation extremes based on satellite (CHIRPS) and in situ dataset over Cyprus," Natural Hazards, vol. 83, pp. 53-63, 2016.

[39] F. J. Paredes-Trejo, H. A. Barbosa, and T. V. Lakshmi Kumar, "Validating CHIRPS-based satellite precipitation estimates in Northeast Brazil," Journal of Arid Environments, vol. 139, pp. 26-40, 2017.

[40] K. E. Taylor, "Summarizing multiple aspects of model performance in a single diagram," Journal of Geophysical Research: Atmospheres, vol. 106, no. 7, pp. 7183-7192, 2001.

[41] W. Briggs, Statistical Methods in the Atmospheric Sciences, Elsevier, Amsterdam, Netherlands, 2007.

[42] H. Hersbach, Operational Global Reanalysis: Progress, Future Directions and Synergies with NWP, European Centre for Medium Range Weather Forecasts, Reading, UK, 2018.

[43] H. Hersbach and D. Dee, ERA5 Reanalysis is in Production, ECMWF Newsletter, Reading, UK, 2016.

[44] S. Brönnimann, R. Allan, C. Atkinson et al., "Observations for reanalyses," Bulletin of the American Meteorological Society, vol. 99, no. 9, pp. 1851-1866, 2018. 

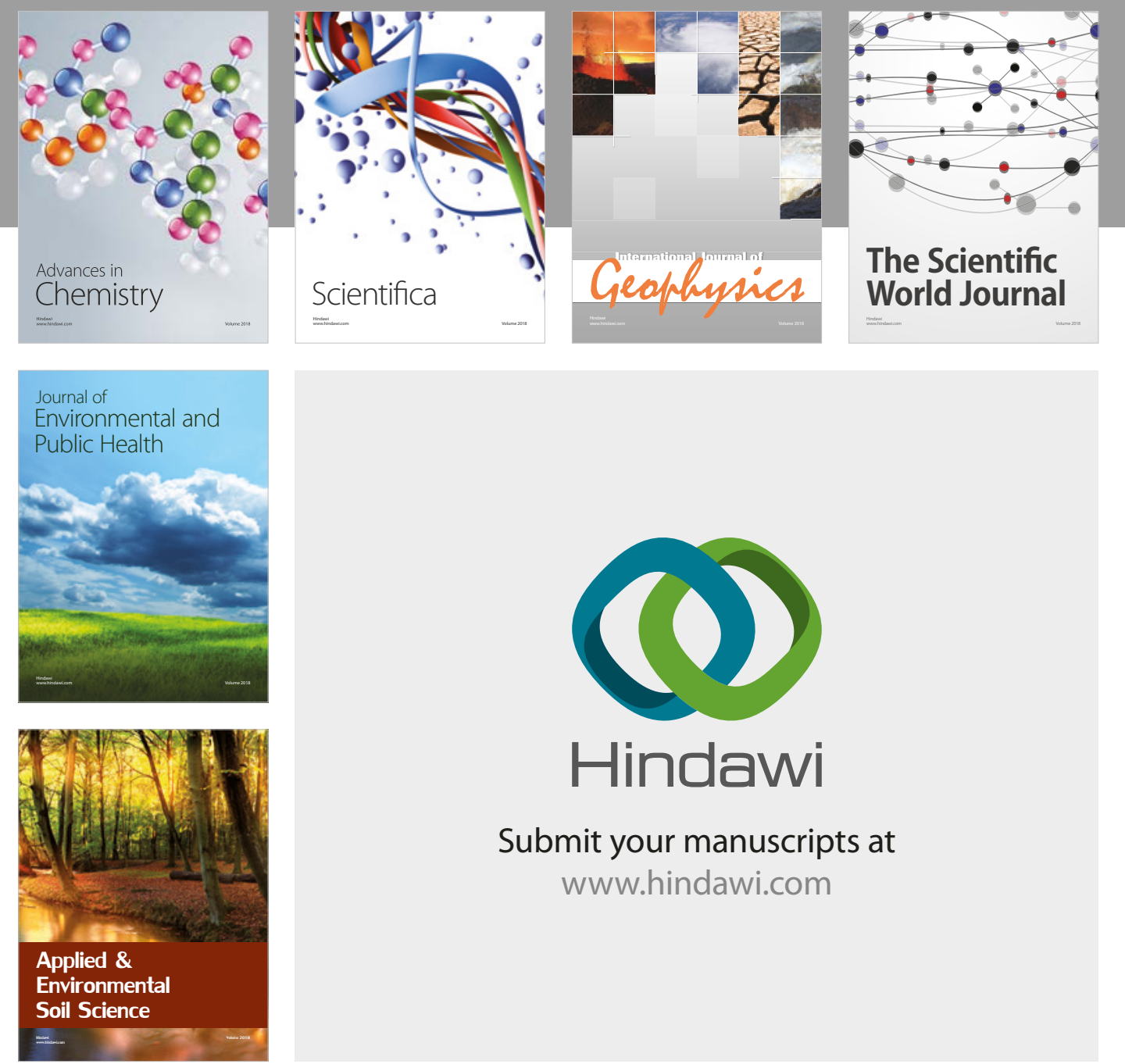

The Scientific

\section{World Journal}
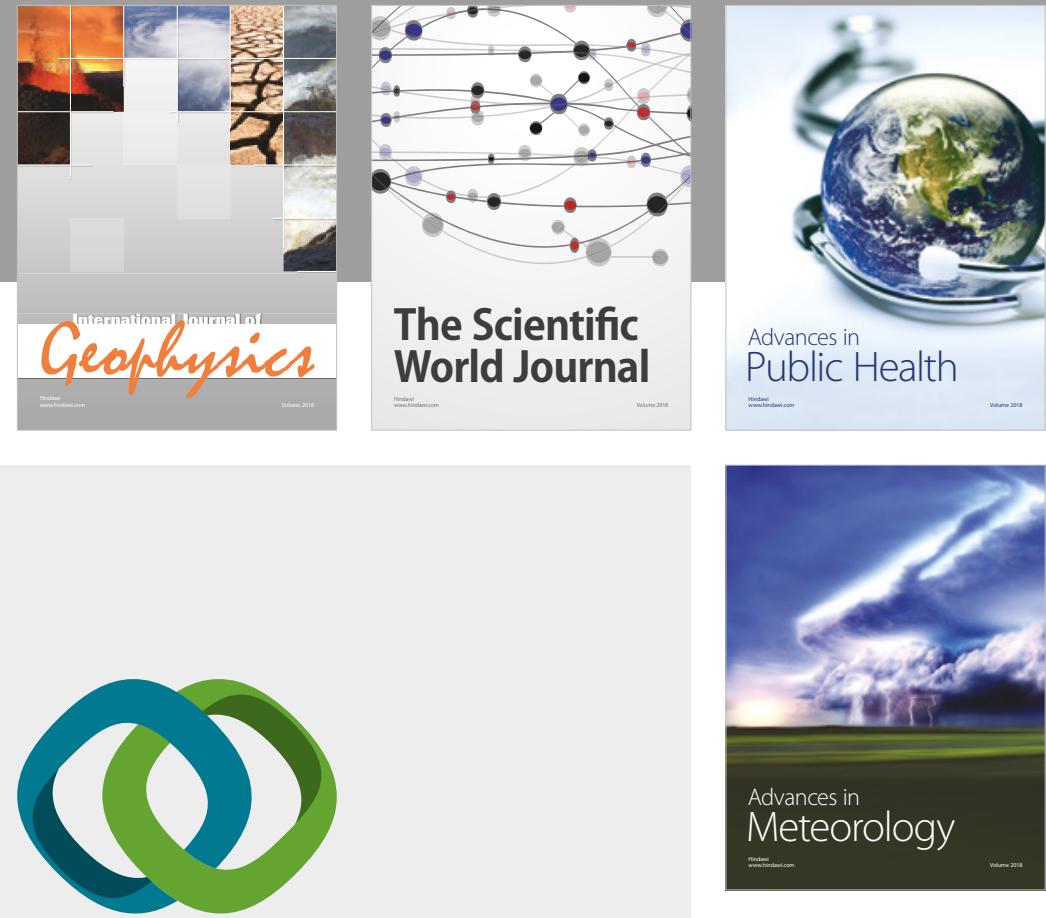

Advan

Public Health

\section{Hindawi}

Submit your manuscripts at

www.hindawi.com
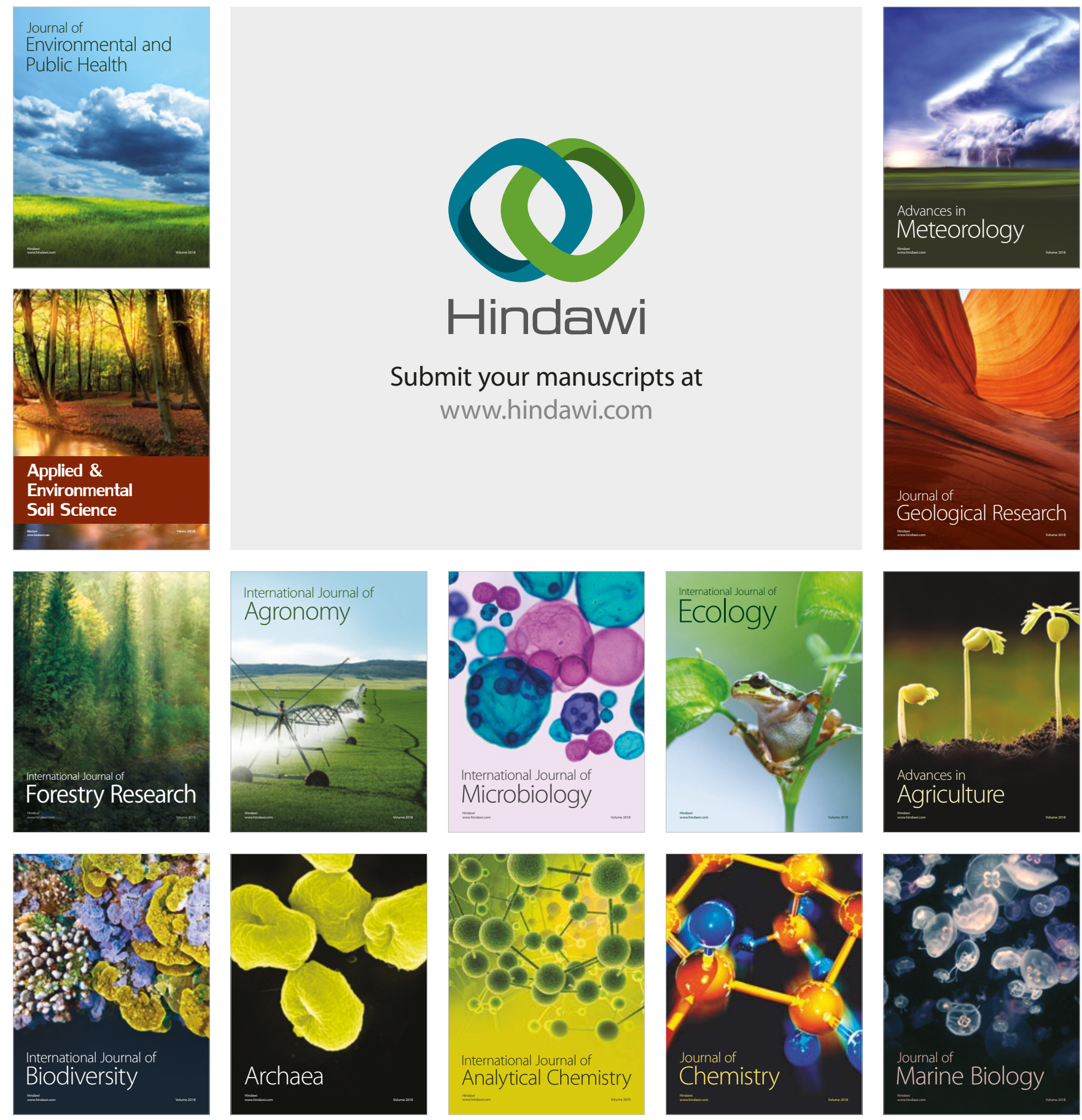